\title{
The synthetic histone-binding regulator protein PcTF activates interferon genes in breast cancer cells
}

\author{
Kimberly C. Olney ${ }^{2}$, David B. Nyer ${ }^{1}$, Daniel A. Vargas ${ }^{1}$, Melissa A. Wilson Sayres ${ }^{2,3}$ and Karmella A. Haynes ${ }^{1 *}$ (D
}

\begin{abstract}
Background: Mounting evidence from genome-wide studies of cancer shows that chromatin-mediated epigenetic silencing at large cohorts of genes is strongly linked to a poor prognosis. This mechanism is thought to prevent cell differentiation and enable evasion of the immune system. Drugging the cancer epigenome with small molecule inhibitors to release silenced genes from the repressed state has emerged as a powerful approach for cancer research and drug development. Targets of these inhibitors include chromatin-modifying enzymes that can acquire drug-resistant mutations. In order to directly target a generally conserved feature, elevated trimethyl-lysine 27 on histone H3 (H3K27me3), we developed the Polycomb-based Transcription Factor (PcTF), a fusion activator that targets methyl-histone marks via its N-terminal H3K27me3-binding motif, and co-regulates sets of silenced genes.

Results: Here, we report transcriptome profiling analyses of PcTF-treated breast cancer model cell lines. We identified a set of 19 PCTF-upregulated genes, or PUGs, that were consistent across three distinct breast cancer cell lines. These genes are associated with the interferon response pathway.
\end{abstract}

Conclusions: Our results demonstrate for the first time a chromatin-mediated interferon-related transcriptional response driven by an engineered fusion protein that physically links repressive histone marks with active transcription.

Keywords: Chromatin, Breast cancer, Polycomb, Tumor suppressor genes

\section{Background}

In addition to DNA lesions, disruption of chromatin at non-mutated genes can support the progression of cancer. Chromatin is a dynamic network of interacting proteins, DNA, and RNA that organizes chromosomes within cell nuclei. These interactions regulate gene transcription and coordinate distinct, genome-wide expression profiles in different cell types. Chromatin mediates epigenetic inheritance $[1,2]$ by regulating expression states that persist through cellular mitosis and across generations of sexually reproducing organisms [3, 4]. Posttranslational modifications (PTMs) of histones within nucleosomes, the fundamental subunits of chromatin, play a central role in the epigenetic regulation of genes that control cell differentiation $[5,6]$. Several landmark studies have revealed that hyperactivity of the

\footnotetext{
*Correspondence: karmella.haynes@asu.edu

'School of Biological and Health Systems Engineering, Arizona State

University, 501 E Tyler Mall, Tempe, AZ 85287-9709, USA

Full list of author information is available at the end of the article
}

histone-methyltransferase enhancer of zeste 1 and 2 (EZH1, EZH2), which generates the histone PTM H3K27me3, is a feature shared by many types of cancer (recently reviewed in [7]). In breast cancer, elevated EZH2 has been linked to cell proliferation and metastasis $[8,9]$ and a poor prognosis for breast cancer patients [10-13]. In stem cells and cancer cells, EZH2 generates H3K27me3 marks at nucleosomes (Fig. 1) near the promoters of developmental genes, represses transcription, and thus prevents differentiation to support the proliferative state in stem cells or neoplasia in cancer (reviewed in [5]). Polycomb Repressive Complex 1 (PRC1, also known as PRC1.2 or PRC1.4 [14]) binds to the H3K27me3 mark through the polycomb chromodomain (PCD) motif of the CBX protein to stabilize the repressed state. Silencing is reinforced by other chromatin regulators including histone deacetylase (HDAC) and DNA methyltransferase (DMT) [15] (Fig. 1).

The PRC module is a group of genes that is regulated by H3K27me3 and Polycomb transcriptional regulators

(c) The Author(s). 2018 Open Access This article is distributed under the terms of the Creative Commons Attribution 4.0 International License (http://creativecommons.org/licenses/by/4.0/), which permits unrestricted use, distribution, and 


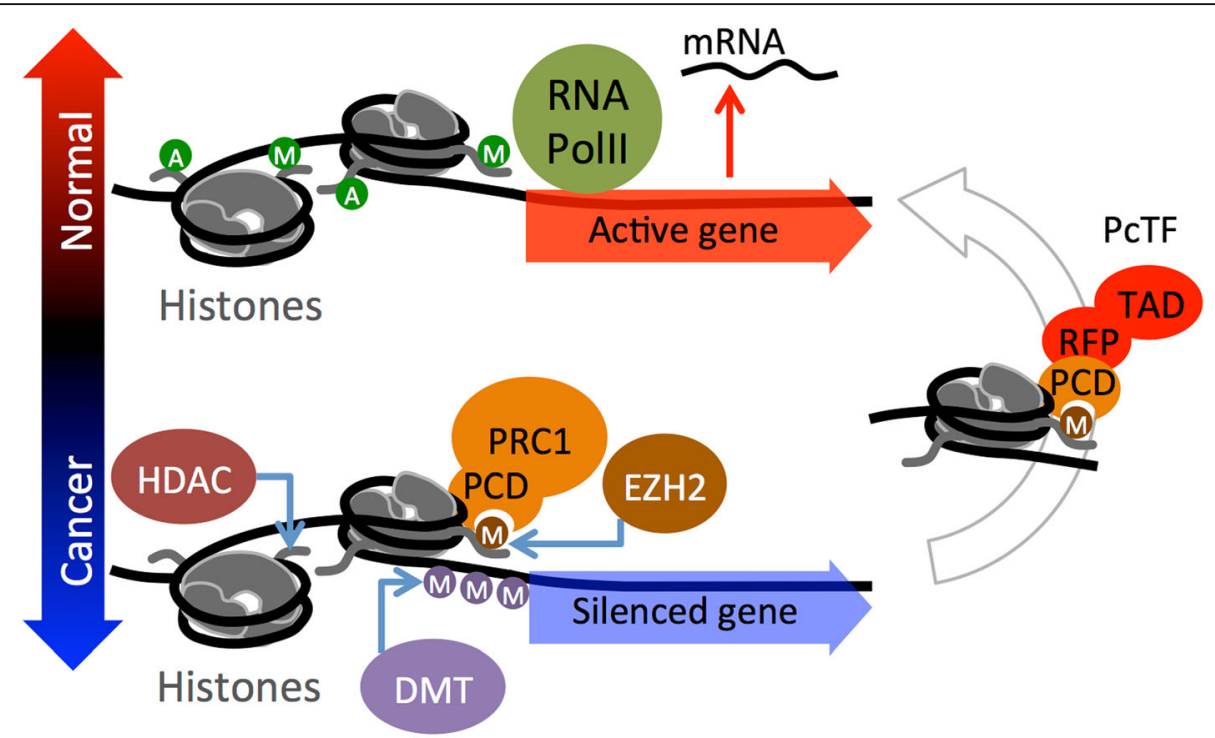

Fig. 1 Reversal of a cancer-associated epigenetic state via the PcTF fusion protein. The lower half of the cartoon depicts the accumulation of repressive chromatin at a developmental gene. EZH2 generates H3K27me3, which is recognized by the PCD fold in the CBX protein of Polycomb Repressive Complex 1 (PRC1). Silencing is re-enforced by histone deacetylase (HDAC), and DNA methyltransferase (DMT) activity. The fusion protein PCTF contains an N-terminal PCD fold (cloned from CBX8) that binds H3K27me3 and stimulates transcription via its C-terminal activator domain to restore the active state (right side of the cartoon). A, acetylation; M, methylation; green circle, activation-associated PTM; orange or purple circle, repression-associated PTM; RFP, red fluorescent protein tag; TAD, transcriptional activation domain VP64

$[16,17]$. Relatively high expression or upregulation of PRC module genes is associated with a non-proliferative state, cell adhesion, organ development, and normal anatomical structure morphogenesis [16]. Knockdown (depletion) of chromatin proteins (reviewed in $[17,18]$ ) and inhibition of Polycomb proteins with low molecular weight compounds and peptides [19-21] stimulates expression of developmental genes and perturbs cancer-associated cell behavior. The interferon (IFN) pathway is often highly represented among silenced genes in cancer. IFN gene activity has been linked to apoptosis [22, 23] and triggers the body's immune system to attack cancer cells $[24,25]$. Decreased expression and increased levels of repressive epigenetic marks (e.g., DNA methylation) have been detected at IFN genes in Li-Fraumeni fibroblasts (39 of 85 silenced genes) [26], colon carcinomas [27], and triple negative breast cancers [28, 29]. Transgenic overexpression of IFN1 in MCF7 breast cancer xenografts perturbs tumor growth in nude mice [23]. Treatment of cancerous cells with broad-acting epigenetic inhibitors of DNA methyltransferase (DNMTi) and histone deacetylase (HDACi) leads to activation of IFN genes which arrests cancer cell proliferation or sensitizes cancer cells to immunotherapy $[25,30,31]$.

The use of the FDA-approved DNA methyltransferase inhibitors (e.g., 5-azacytidine) to treat cancer, as well as the success of other epigenetic interventions in clinical trials [32, 33] demonstrates that chromatin is a druggable target in cancer. Certain limitations of epigenetic inhibitor compounds could encumber the efficacy of epigenetic therapy. Inhibitors do not interact directly with modified histones, indirectly activate silenced genes by blocking repressors, generate incomplete conversion of silenced chromatin into active chromatin [34,35], interact with off-target proteins outside of the nucleus [36], and do not affect resistant Polycomb protein mutants [37-39]. These limitations could be addressed by technologies that directly target H3K27me3 within the chromatin fiber. H3K27me3 is a highly conserved feature in cancers [7]. Even in cases where H3K27 becomes mutated to methionine in one allele [40, 41], methylation of the wild-type copy of H3K27 is still present at repressed loci in cancer cells $[42,43]$.

Our group developed a fusion protein called Polycomb-based Transcription Factor (PcTF), which specifically binds H3K27me3 [44] and recruits endogenous transcription factors to PRC-silenced genes (Fig. 1). In bone, brain, and blood-cancer derived cell lines, PcTF expression stimulates transcriptional activation of several anti-oncogenesis genes [45]. PcTF-mediated activation leads to the eventual loss of the silencing mark H3K27me3 and elevation of the active mark H3K4me3 at the tumor suppressor locus CASZ1.

To explore the therapeutic potential of fusion protein-mediated epigenetic interventions, we sought to investigate the behavior of PcTF in breast cancer cells lines that have been established as models for 
tumorigenesis [46-48]. Here, we extend our investigation of PcTF activity to three breast cancer-relevant cell lines. First, we investigated the transcription profiles of predicted PRC module genes in drug-responsive (MCF-7, BT-474) and unresponsive triple negative (BT-549) breast cancer cell lines. Receptor-negative BT-549 cells have a transcription profile and histology similar to aggressive tumor cells from patient samples $[49,50]$. Overexpression of PcTF in transfected breast cancer cells led to the upregulation of dozens of genes, including a common set of 19 genes in the interferon response pathway, as early as $24 \mathrm{~h}$ after transfection. The transcriptome of BT-549 (triple-negative) showed the highest degree of PcTF-sensitivity. We observed that PcTF-sensitive genes are associated with a bivalent chromatin environment and moderate levels of basal transcription. Interestingly, these PcTF-sensitive genes do not overlap with very strongly repressed, PRC-enriched loci. This discovery provides new mechanistic insights into the state of genes that are poised for transcriptional activation via PcTF.

\section{Results}

Differential regulation of genes in breast cancer cell lines

To determine expression levels of predicted PRC module genes, we profiled the transcriptomes of three breast cancer cell lines and the non-invasive, basal B cell line MCF10A [51] using next-generation deep sequencing of total RNA (RNA-seq). MCF7, BT-474, and BT-549 represent luminal A, luminal B, and basal B subtypes of breast cancer, respectively (Table 1) [46]. Previous studies have shown that gene expression profiles distinguish two major categories of cancer cell lines, luminal and basal, in patient-derived samples $[52,53]$. The basal class exhibits a stem-cell like expression profile [54], which is consistent with high levels of Polycomb-mediated repression at genes involved in development and differentiation [55, 56]. Levels of the repressor protein EZH2 and the histone modification that it generates (H3K27me3) are elevated in MCF7, BT-474, and BT-549 compared to non-metastatic cells such as MCF10A (Table 1). A mechanistic link between Polycomb-mediated repression and tumor aggressiveness has been supported by a study where stimulation of the phosphoinositide 3-kinase (PI3K) signaling pathway, which induces a metastatic phenotype in MCF10A, is accompanied by increased H3K27me3 at several target genes $[57,58]$. We hypothesized that known Polycomb-repressed genes (the PRC module) would be down-regulated in the cancerous cell lines compared to MCF10A.

Comparison of the expression profiles in untreated cells showed that the three breast cancer model cell lines were transcriptionally dissimilar to the control cell line MCF10A and that BT-549 and MCF7 were more similar to each other than either were to BT-474. Expression levels (FPKM values) across 63,286 gene protein coding transcripts (GRCh38 reference genome) were used to calculate Jensen-Shannon Divergence (JSD) (Methods and Fig. 2a). JSD values correspond to the similarity of the probability distributions of transcript levels for two RNA-seq experiments. Expression values for biological replicates showed the highest similarities (smallest distances) within cell types (Fig. 2a, upper grid). The largest distances were observed between MCF10A and the three cancer cell types: 0.461 for BT-549, 0.476 for MCF7, and 0.511 for BT-474 (Fig. 2a, lower grid). A similarly high JS distance was observed for BT-549 versus BT-474 (JSD $=0.464$ ), suggesting that these cancer cell lines are transcriptionally distinct. BT-549 and MCF7 showed the highest similarity, with a cumulative JSD of 0.357 . This observation contrasts with other reports where BT-549 and MCF7 are described as transcriptionally [63] and phenotypically different [64]. Differences in transcription profiling methods, RNA-seq used here and the DNA oligomer microarray chip used by others, may underlie the different outcomes. Specifically, our Jensen-Shannon Distance analysis is based on 63,286 expressed sequences, whereas the number of genes (or "probesets") represented on microarrays used in the cited study by Kenny et al. 2007 (14,500 genes on the HG-U133A array) is less than half of this number. Transcript coverage is higher for RNA-seq than in microarrays (discussed in [65]). The detection of additional transcripts may have influenced the apparent transcriptional similarities and differences between cell types.

Differential expression between cell lines for individual genes (Additional file 1: Figure S1) followed similar trends as those observed for the global JSD analysis. We

Table 1 Descriptions of the breast tissue-derived cell lines used in this study

\begin{tabular}{|c|c|c|c|c|c|}
\hline Cell line & ATCC & Sub-type & Markers [46] & EZH2 & H3K27me3 \\
\hline MCF7 & HTB-22 & Luminal A & ER+, PR+ & Elevated $^{a, b, c}[59-61]$ & Elevated $^{\mathrm{a}}[57,60]$ \\
\hline BT-474 & HTB-20 & Luminal B & ER+, PR+, HER2+ & Elevated $^{c}[62]$ & Elevated $^{d}[57]$ \\
\hline BT-549 & HTB-122 & Basal B, claudin-low & ER-, PR-, TP53 ${ }^{M}$ & Elevated ${ }^{c}[8]$ & Elevated $^{d}[57]$ \\
\hline MCF10A & CRL-10317 & Non-invasive/ Basal B & ER-, PR- & $\mathrm{n} / \mathrm{a}$ & $\mathrm{n} / \mathrm{a}$ \\
\hline
\end{tabular}

ATCC American Tissue Culture Center ID. Molecular subtype and marker expression status are from Neve et al. 2006 [46]: Estrogen receptor presence or absence $(\mathrm{ER}+/-)$, Progesterone receptor presence or absence (PR+/-), HER2 overexpression (HER2+), and TP53 mutation (TP53 $\left.{ }^{M}\right)$. EZH2 and H3K27me3 were shown to be elevated compared to non-metastatic fibroblasts (a) [60], LNCaP (b) [59], MCF10A (c) [8, 61, 62], and HMEC (d) 


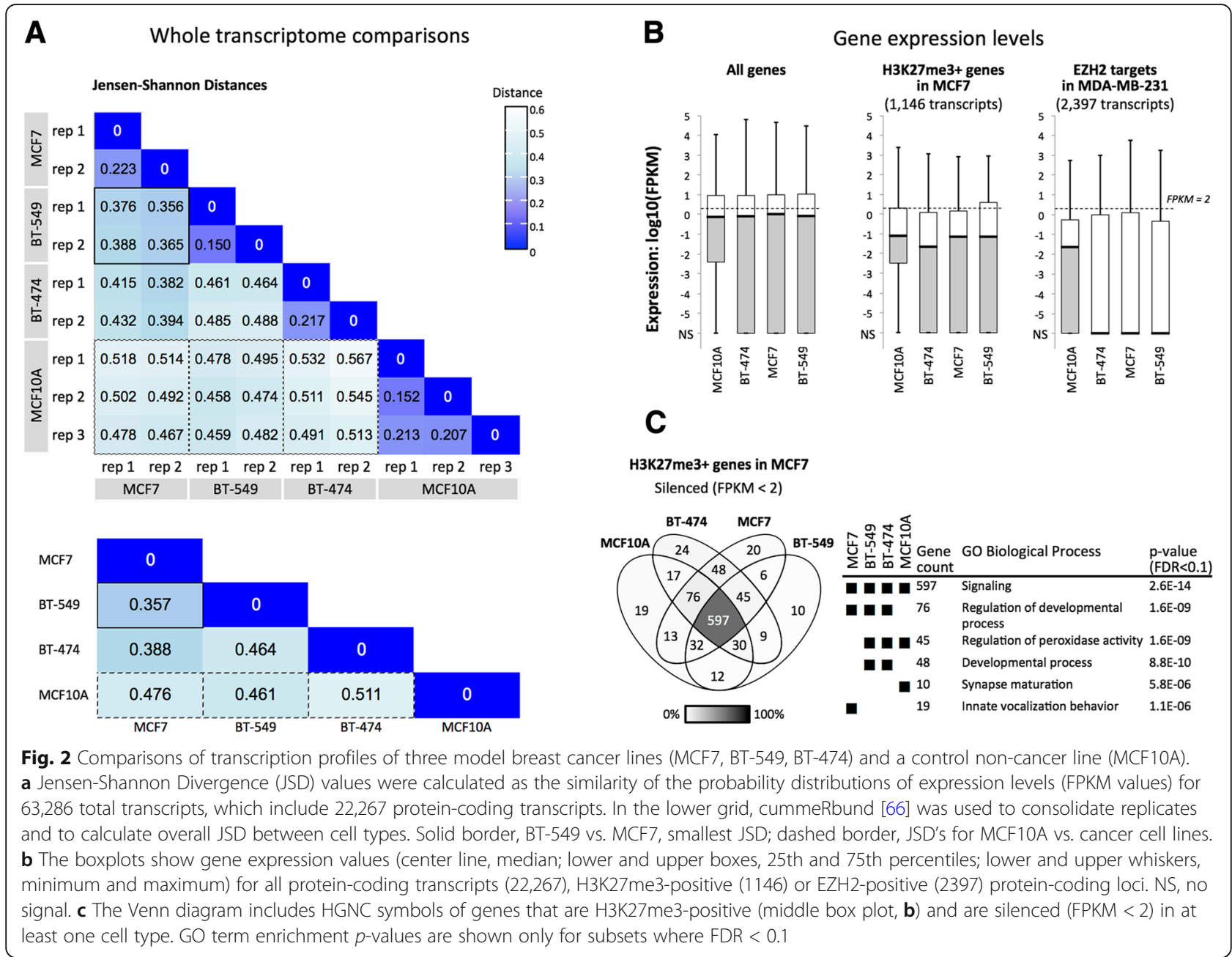

used an expression comparison algorithm (Cuffdiff [67]) to identify genes that were differentially expressed (2-fold or greater difference in expression, $q$ value $\leq 0.05$ ) or similarly expressed (less than 2-fold difference, $q$ value $\leq 0.05$ ) between cell types. Comparisons that included MCF10A showed the highest numbers of differentially-expressed genes, as well as the lowest numbers of similarly expressed genes. This result further supports transcriptional differences between the cancerous cell lines and MCF10A (Additional file 1: Figure S1).

Next, we determined expression levels within groups of predicted PRC-regulated genes and observed that expression within these subsets is lower in the three cancer cell types than in MCF10A. We used data from other breast cancer cell line studies of MCF7 and MDA-MB-231 to classify a subset of PRC target genes based on H3K27me3 enrichment or binding of EZH2, an enzyme that generates the H3K27me3 mark (see Methods). Only 245 gene IDs were shared between the H3K27me3 and EZH2 subsets. Although these two groups are mostly distinct, both showed low median expression values (FPKM $<2$ ), which suggests epigenetic repression (Fig. 2b). Median expression levels of predicted PRC module genes were reduced in the cancer cell lines compared to the non-cancer cell line. The H3K27me3-marked subset showed median log10(FPKM) values for BT-474 (-1.66), MCF7 (-1.16), and BT-549 $(-1.15)$ that were slightly lower than MCF10A $(-1.10)$ (Fig. 2b, middle plot). The median FPKM values for ZH2 targets were dramatically lower (zero signal) in the cancer cell lines, while the median value was higher $(-1.65)$ for MCF10A (Fig. 2b, right). Overall, H3K27me3 and EZH2 enrichments from two breast cancer cell lines (MCF7 and MDA-MB-231) correspond to relatively low expression in all three breast cancer cell lines studied here. This result is consistent with the roles of H3K27me3 and $\mathrm{EZH} 2$ in cancer-associated gene silencing.

To determine whether individual predicted PRC target genes were similarly regulated across cell lines, we compared two groups of genes that were categorized by expression level: silenced $($ FPKM $<2)[68,69]$ or expressed (FPKM $\geq 2$ ) (Additional file 1: Figure S2). In each cell 
type, genes with silenced expression levels included 70.2$79.3 \%$ of the H3K27me3-marked loci (Additional file 1: Figure S2) and 78.4-82.2\% of the EZH2-enriched loci. About one quarter of the genes (17.8-29.8\%) showed some expression (FPKM $\geq 2$ ) and only $16.7-8.2 \%$ were expressed at FPKM $\geq 10$. The set of $45 \mathrm{H} 3 \mathrm{~K} 27 \mathrm{me} 3$-enriched repressed genes shared by the three cancer cell lines BT-474, BT-549, and MCF7 (Additional file 1: Table S1) shows strong representation of the gene ontology processes "regulation of peroxidase activity" (GOrilla [70], $p=5.84 \mathrm{E}-6$, FDR = 8.85E-2; Fig. 2c) and "ectoderm development" (Panther [71], $p=1.07 \mathrm{E}-4$, FDR $=2.61 \mathrm{E}-2)$. The silencing of lipoxygenase (ALOXE3) and and inhibitor of peroxidase (LRRK2) may contribute to elevated pro-cancer COX-mediated peroxidase activity [72, 73]. Low levels of ALOXE3, ADRB2, BNC1, BTC, CCNO, ETV4, MCI$D A S, P I D 1, S P R R 2 D$, and ZBTB16 are consistent with the epigenetic repression of pro-differentiation pathways in cancer cells. We hypothesized that these PRC-module genes would become activated in the presence of the synthetic regulator PcTF, which interacts with the repressive H3K27me3 mark.

\section{PcTF-sensitive interferon response genes are shared across three cancer cell types}

We investigated changes in the transcriptomes of PcTF-expressing breast cancer cells over time. We transfected cells with PcTF-encoding plasmid DNA (previously described [45]) and allowed them to grow for 24, 48, and $72 \mathrm{~h}$ before extracting total RNA for sequencing. RNA-seq reads were aligned to a human reference genome (GRCh38) that included the coding region for PcTF (see Methods). No reads aligned to the PcTF coding sequence in control, untransfected cells. In the transfected cells, PcTF expression levels were highest at $24 \mathrm{~h}$ and decreased 1.6 to 5.5 -fold every $24 \mathrm{~h}$ (Fig. 3a). We observed a similar trend with other cancer cell lines in a previous study [45]. One outlier sample, a replicate for BT-474 cells expressing PcTF for $48 \mathrm{~h}$, had a markedly different PcTF expression level (Fig. 3a) and genome-wide transcription profile (Additional file 1: Figure S3) and was therefore omitted from further analyses.

Nineteen genes were upregulated at least 2-fold ( $q$ value $\leq 0.05$ ) at all time points in all three cell lines (Fig. $3 \mathrm{~b}$ ): C19orf66, DDX58, DTX3L, HERC6, IFI27, IFI44L, IFI6, IFIH1, ISG15, LGALS3BP, MX1, OAS1, OAS3, PARP9, PARP14, PLSCR1, SP100, UBE2L6, and XAF1. Here, we refer to this subset PcTF-upregulated genes, or PUGs. Expression of these 19 genes in the untreated BT-549 and MCF7 samples are quite dissimilar, while the overall BT-549 and MCF7 transcriptional profiles were relatively similar (JSD analysis, see Fig. 2a). However, it is not surprising that a small group of genes would show a different pattern than when similarity was computed across the entire genome.
The most significantly enriched GO terms for this set include "defense response to virus" and "negative regulation of viral life cycle" (Fig. 3c). An investigation of regulator motif enrichment at the promoters of PUGs revealed that the transcription factors that were predicted to bind the overrepresented motifs were involved in immune response and tissue development processes (Fig. 3d, Additional file 1: Figure S4 and Additional file 1: Table S2). Fifteen of the 22 transcription factors showed detectable levels of expression in all three cell lines (Additional file 1: Figure S5). IRF1, IRF7, IRF9, and $P R D M 1$ showed significant upregulation $(\mathrm{FC} \geq 2, \mathrm{q} \leq$ 0.05) in PcTF-expressing cells. Promoter motifs for IRF1 and IRF3 were present at all 19 PUGs (Fig. 3e). Therefore, regulation of PUGs may be primarily driven by PCTF-mediated activation of IRF1.

Different subsets of genes were up- or down-regulated at least two-fold ( $q$ value $\leq 0.05$ ) early, late, or across all time points during PcTF expression (Fig. 4). Of the genes that showed at least a two-fold change in either direction, the vast majority were up-regulated (Fig. 4a). We also observed that depending on the cell line, two or three predicted regulators of PUGs, including IRF1, IRF7, IRF9, and $P R D M 1$, became significantly upregulated (Fig. 4b). This result suggests that the IFN response might be mediated through upregulation of master regulators. Thus, PcTF may target silenced chromatin at IRF1, IRF7, IRF9, and PRDM1 and not necessarily at PUGs.

Our results also show that the PcTF-activated genes had virtually no overlap with the $45 \mathrm{H} 3 \mathrm{~K} 27 \mathrm{me} 3$-enriched, silenced genes (FPKM <2) shared by the three cancer cell lines (Fig. 2c, Additional file 1: Table S1). Only one of these 45 genes, PID1, became upregulated in any cell line (BT-549 at 48 and $72 \mathrm{~h}$ ). In this study we observed that the genes that were up-regulated came from the pool of lowto moderate-expressing genes. So far, our results suggest that PcTF-mediated activation requires a moderate level of basal expression at the target gene. This idea may be counterintuitive since H3K27me3 mark, the target of PcTF [44], is essential for transcriptional repression according to the long-established model for Polycomb-mediated regulation [75]. However, a recent study using genome-wide ChIP-seq and transcription profiles in murine cells showed that H3K27me3 was enriched at genes with low levels of expression and depleted at completely silenced or highly expressed genes [76]. We were prompted to investigate whether the chromatin features at PcTF-activated genes might reflect a low to moderate expression state.

\section{PcTF-sensitive loci bear repression- and activation- associated chromatin features}

To investigate the contribution of local chromatin states to PcTF-mediated gene regulation, we analyzed histone modifications and RNA polymerase II enrichment at 

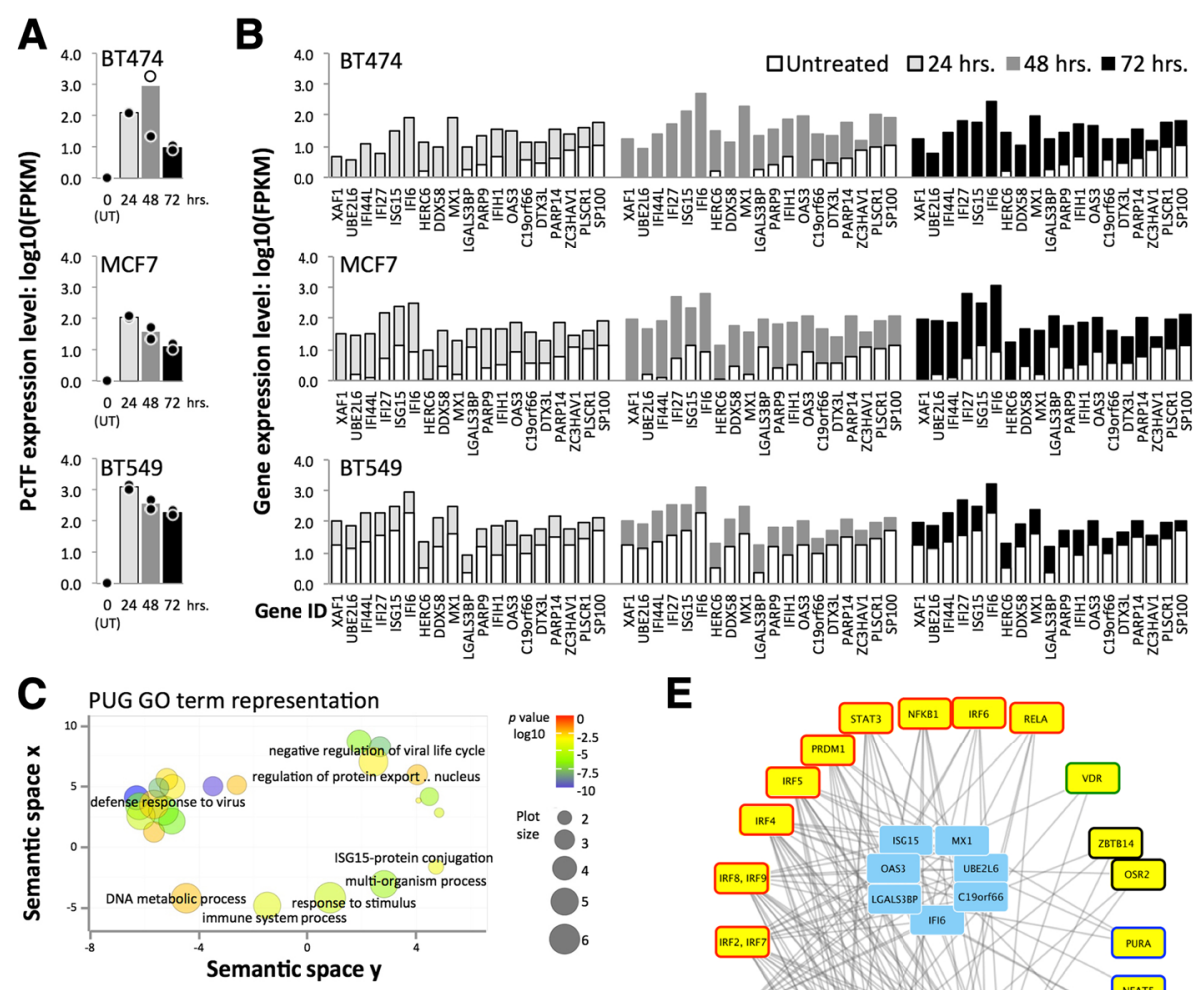

$\mathbf{E}$
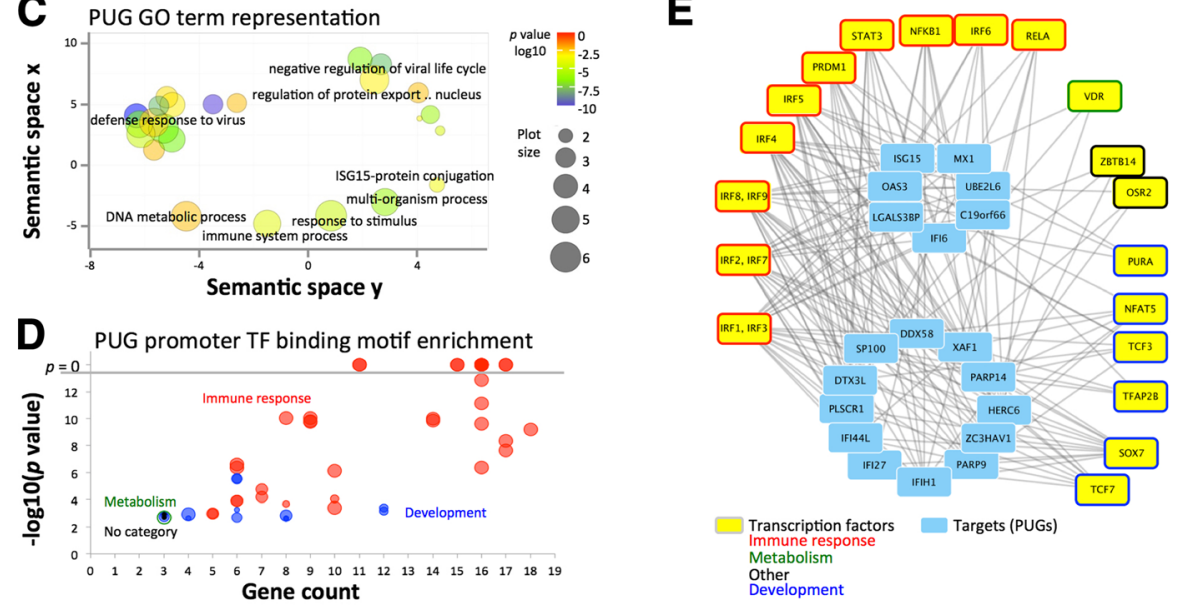

Fig. 3 PcTF-expressing breast cancer cell lines show upregulation of interferon (IFN) pathway genes. a Charts show log 10 (FPKM) of PCTF for untransfected cells (UT) and at 24, 48, and $72 \mathrm{~h}$ following transfection of each cell line. The outlier for BT-474 (48 h, replicate 1) was omitted from subsequent analyses. Dots, each replicate library; bars, mean of values from the two replicates. b Mean log10(FPKM) values are shown for 19 Polycomb-upregulated genes genes (PUGs; FC $\geq 2, q \leq 0.05$ at all time points in all three cell lines), sorted from lowest to highest average expression level in untreated cells. c Gene ontology $(\mathrm{GO})$ Biological Process term enrichment for the 19 PUGs is represented the bubble chart. GO clusters and representative terms (black labels) are plotted based on semantic similarities in the underlying GOA database. d Overrepresentation of transcription factor (TF) binding motifs [74] at the promoters of PUGs ( $p$-value $<0.05 / 19.0$, Bonferroni correction). e Transcription factors (outermost boxes) associated with promoter motifs from panel $D$ are shown in the network graph

PcTF-upregulated genes in MCF7. Here, we utilized the extensive public ChIP-seq data that is available for the MCF7 cell line to investigate chromatin features. The 125 genes that were significantly upregulated (FC $\geq 2, q \leq 0.05)$ at one, two, or all time points in MCF7 (see Fig. 4b) showed a range of H3K27me3 mean enrichment values across $10 \mathrm{~kb}$ centered around each transcriptional start site (Fig. 5a). Consistent with PUGs, the 106 additional upregulated genes showed significant overrepresentation of interferon response-related processes (GO biological process "type I interferon signaling pathway," $p=4.08 \mathrm{E}-28, \mathrm{FDR}=6.21 \mathrm{E}-24)$.

Genes within the highest $20 \%$ of mean values for H3K27me3 included the predicted regulator IRF1
(Fig. 3d, e) and 5 of the 19 PUGs. Other PcTF-responsive genes that lack the H3K27 methylation mark might represent downstream targets of the products expressed from targets of PcTF. Mean enrichments of H3K9me3 (Fig. 5a), a modification that is frequently found at constitutive pericentric heterochromatin and non-coding DNA [77-79], showed no pattern that resembled H3K27me3. PcTF-responsive genes tended to be distributed along chromosome arms rather than concentrated near centromeres (Additional file 1: Figure S6). This suggests that PcTF target sites coincide more closely with the distribution of facultative chromatin and epigenetically-regulated cell development genes [55, 80]. 




Enrichments for the features associated with active expression, H3K27ac, H3K4me3, and RNA Pol II were stronger at PcTF-responsive genes than at PcTF non-responsive genes (Fig. 5b). Regions containing PcTF-activated genes include interspersed peaks of H3K27me3 and H3K4me3 (Additional file 1: Figure S7), which is characteristic of bivalent domains that are poised for activation [15, 81]. We conclude that under the conditions tested here, strongly repressed genes are resistant to PcTF-mediated activation while an intermediate regulatory state, where silent and active marks are present, supports PcTF activity.

Two substantially different mechanisms might account for the results observed so far. First, target gene activation may depend upon PcTF's interaction with and disruption of silenced chromatin. In previous work, we established that PcTF activity requires the histone-binding PCD domain $[45,82]$ and the presence of H3K27me3 near the target gene [82] to disrupt epigenetic silencing. Work reported by others demonstrated activation of interferon networks through the disruption of chromatin-mediated repression with small molecule inhibitors. Treatment of breast cancer cell lines (including BT-474 and MCF7) with DNA methyltransferase (5-azacitidine) led to activation of $D D X 58$, IFI27, IFI6, IFIH1, ISG15, MX1, OAS3, UBE2L6, XAF1 (9 of the 19 PUGs), and other genes [30]. Furthermore, inhibitors of histone deacetylase, a class of enzymes that support repressed chromatin, stimulate rapid activation of interferon (IFN) genes in human and mouse cells [83].

Second, introduction of foreign nucleic acids into the cells could have indirectly stimulated the interferon response via sequence non-specific effects [84-88] without interaction of PcTF with chromatin. Microarray-based transcriptome profiling of MCF7 cells transfected with Lipofectamine-pM1-MT vector complexes showed upregulation of HERC6, IFIH1, ISG15, LGALS3BP, MX1, OAS3, PLSCR1, and UBE2L6 [87], which represent 8 of the 19 PUGs. Small RNA-induced knockdown of GAPDH in renal carcinoma cells was accompanied by increased expression of IFI6, OAS3, and UBE2L6 [84]. 


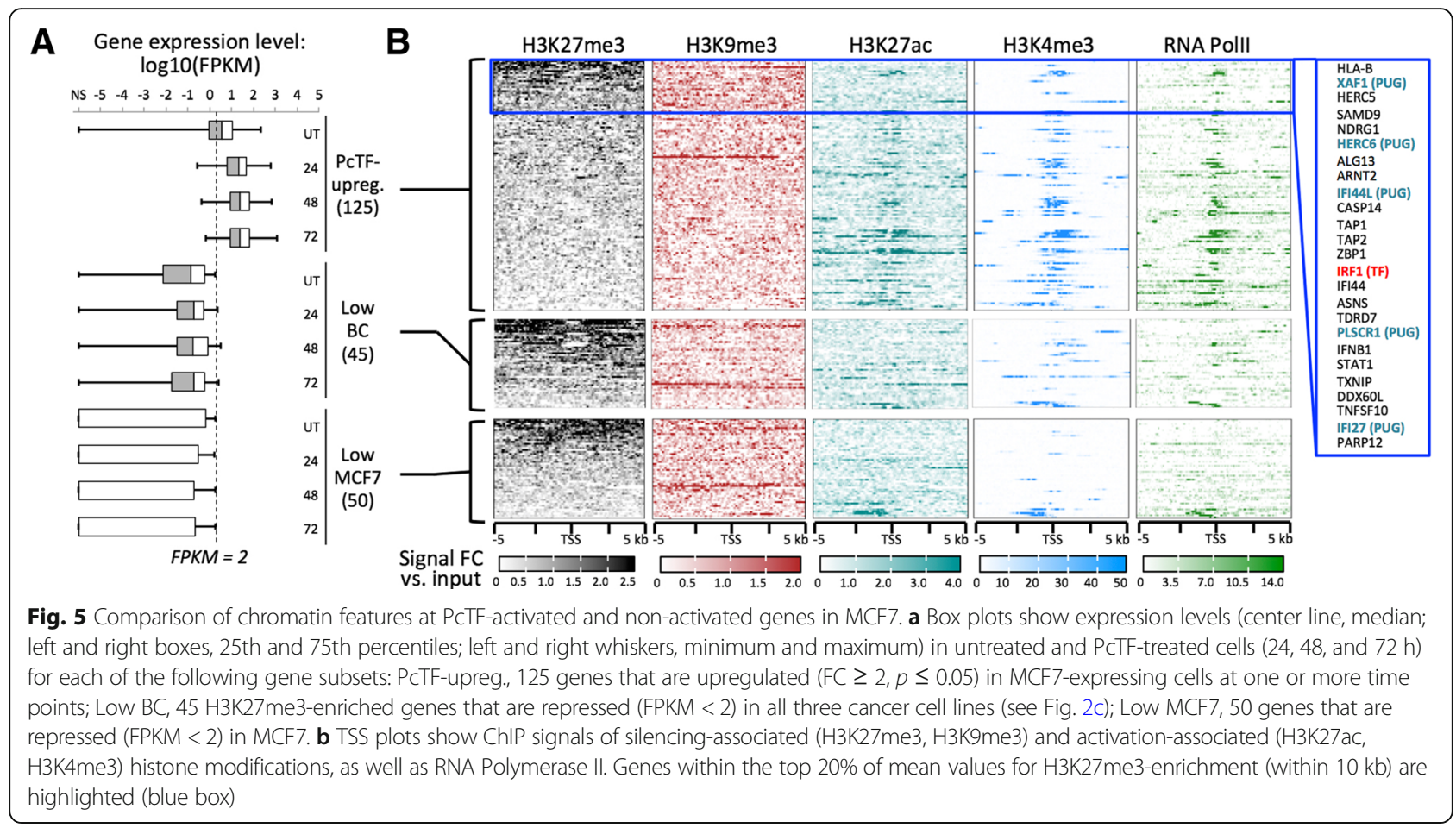

MX1, IRF1 and IRF7 became activated following electroporation (nucleofection) of NIH3T3 cells with control empty plasmids pcDNA3.1 (the origin of the plasmids used in our study), phGF, and pEGFP-N1 [88]. To investigate nonspecific effects from foreign nucleic acids, we used reverse transcription followed by quantitative PCR to measure expression levels of PcTF-responsive genes in cells that expressed a truncated version of PcTF as a control, as described in the following section.

\section{Foreign RNA from a PcTF-deletion mutant is insufficient for sustained expression of XAF1 in MCF7}

We asked whether the presence of the PcTF transgene and its transcribed RNA were responsible for the consistent interferon response in breast cancer cells. Using transient transfections, we had established that PcTF-mediated activation of genes could be detected over background at multiple time points. However, in this experiment PcTF levels decreased over time (Fig. 3a), which prevents us from distinguishing time- versus dose-dependent effects on gene regulation. Therefore, we constructed stable transgenic cell lines to enable constant expression of the fusion protein over time. We were able to generate viable, transgenic lines from MCF7 cells. Expression of PcTF or a control fusion protein that lacks the histone-binding domain $\left(\mathrm{Pc}_{\Delta} \mathrm{TF}\right)$ was placed under the control of the rtTA activator, which binds to the $p$ Tet promoter in the presence of doxycycline (dox) (Fig. 6a). Expression of rtTA was indicated by constitutive GFP expression, and inducible nuclear localization sequence-tagged PcTF was detected as an RFP signal after treatment with doxycycline (Fig. 6b). We used reverse transcription followed by quantitative PCR (RT-qPCR) to measure the expression levels of PcTF and a subset of PcTF-sensitive genes that were identified in the RNA-seq experiment.

RT-qPCR using a universal mCherry-specific primer set confirmed that PcTF expression levels decreased over time in transiently transfected cells (Fig. 6c) as observed for FPKM values from the RNA-seq experiment (Fig. 3a). The stable transgenic cells showed low levels of fusion protein mRNA in the initial uninduced (-dox) state compared to untransfected MCF7 cells. Exposure to $1 \mu \mathrm{g} / \mathrm{mL}$ dox increased PcTF and $\mathrm{Pc}_{\Delta} \mathrm{TF}$ levels by an order of magnitude. These levels were slightly higher than the PcTF expression levels observed in transiently transfected cells at the 72-h time point, and remained relatively constant over time. Fold-change (compared to untransfected cells) remained within values of 67-192 at 24, 48, and $72 \mathrm{~h}$.

For RT-qPCR analysis of PcTF-sensitive targets, we were able to design and validate specific assays for a subset of genes that were significantly upregulated at one or more time points in MCF7, including two PUGs (XAF1, SP100) and others. $X A F 1$ was the most strongly upregulated across all three time points (18 to 36-fold) (Fig. 6d). The other five genes showed slight upregulation in response to dox-induced PcTF expression. The weaker response of these genes compared to XAF1 could be explained by a smaller dynamic range, where there is little difference between the basal versus activated expression level. Furthermore, these genes may have been slightly upregulated 

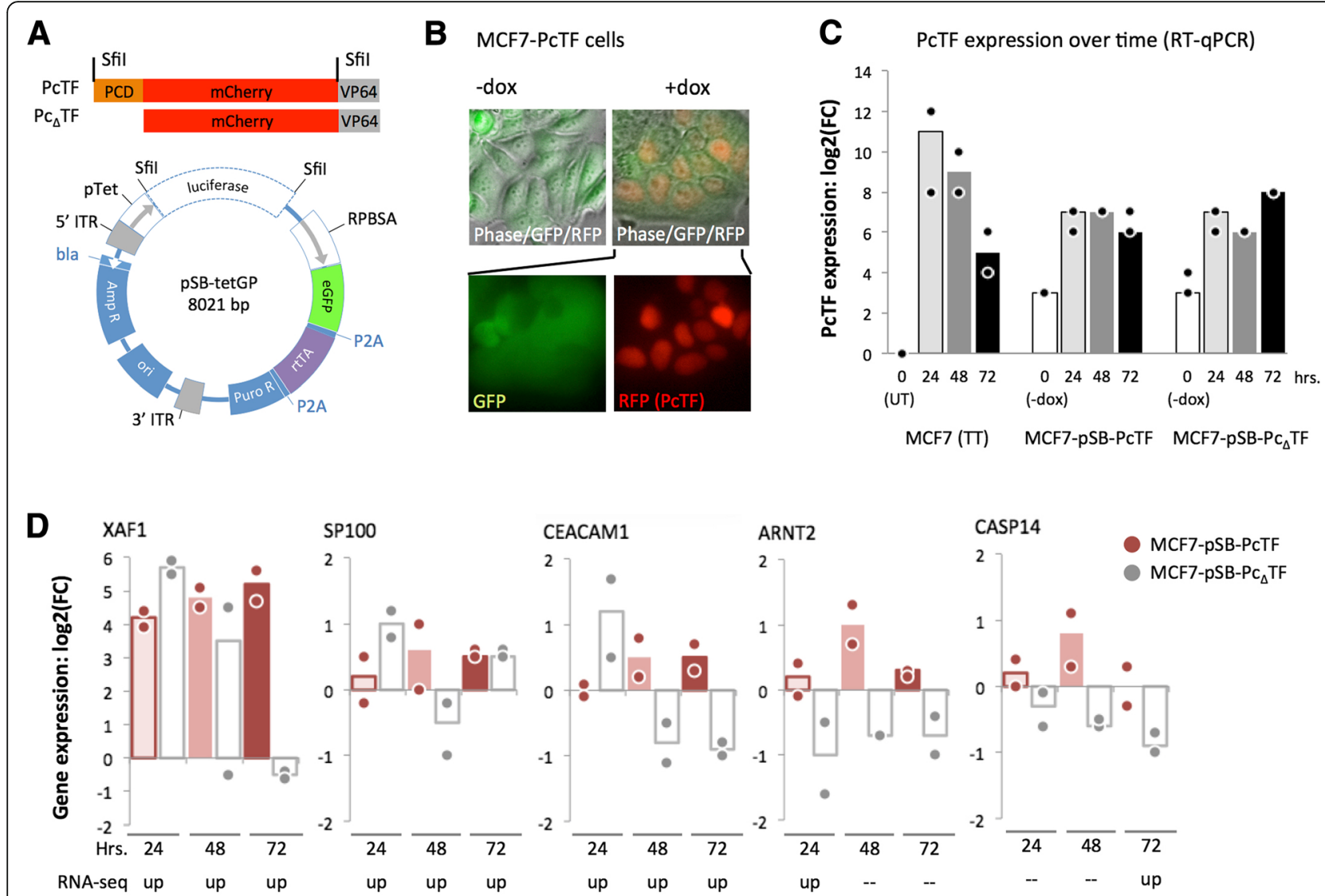

Fig. 6 RT-qPCR analysis of gene expression in stable, transgenic PCTF-expressing cells. a Sfil-flanked PcTF or PC TF constructs (top) were cloned into the pSBtet-GP expression vector (bottom), resulting in the replacement of the luciferase reporter with fusion protein ORFs. $\mathbf{b}$ Fluorescence microscopy of the MCF7-PCTF transgenic cell line. c Time course RT-qPCR for PCTF. $\mathbf{d}$ Time course RT-qPCR for select genes. For all RT-qPCR experiments $n=$ two cDNA libraries from independent transfections or dox treatments. FC, fold change relative to "no dox" controls, calculated as double delta $C_{p}$ (see Methods)

prior to dox treatment since PcTF was detected at low levels before induction (Fig. 6c).

At the $24 \mathrm{~h}$ time point, XAF1, SP100, and CEACAM1 became up-regulated in truncation-expressing cells, suggesting an initial nonspecific response to transgenic $\mathrm{Pc}_{\Delta}$ TF RNA. At 48 and $72 \mathrm{~h}$, gene expression decreased in the presence of $\mathrm{Pc}_{\Delta} \mathrm{TF}$. Over time, expression remained upregulated in the presence of PcTF compared to $\mathrm{Pc}_{\triangle} \mathrm{TF}$ at XAF1, CEACAM1, and ARNT2. Overall, these results suggest that for certain genes (XAF1, CEA$C A M 1$, and $A R N T 2$ ), maintenance of the PcTF-induced activated state requires interaction with chromatin through the H3K27me3-binding PCD motif.

\section{Tumor suppressor and BRCA pathway genes become upregulated in PcTF-expressing cells}

To explore the clinical implications of PcTF-mediated transcriptional regulation, we determined the representation of known tumor suppressor genes amongst PcTF-responsive loci. For this analysis we used a tumor suppressor gene set that includes 983 candidate anti-cancer targets that are down-regulated in tumor samples (Methods). Of these, 589 include BRCA human tumor suppressor genes (TSGs) that are repressed in invasive carcinoma samples compared to normal tissue samples $[89,90]$. The genes were classified as tumor suppressors based on text-mining of cancer research literature, and manual assessment of relevant cancer types and molecular pathways (TSGene 2.0) [89, 90].

To identify TSGs that are upregulated in response to PcTF, we compared the upregulated subset (FC $\geq 2, q \leq$ $0.05)$ to the 983 candidate anti-cancer genes identified by TSGene 2.0. Fifteen of the 983 TSGs were upregulated across all three time points in at least one of the cell lines (Fig. 7a). Information from genecards.org [91] and pathwaycommons.org [92] (Fig. 7b) further validated the association of these 15 genes with tumor suppressor activity. Of the fifteen upregulated TSGs, seven belong to the breast cancer susceptibility (BRCA) pathway: CDKN1A, PML, ANGPTL4, CEACAM1, BMP2, SP100, TFPI2. 


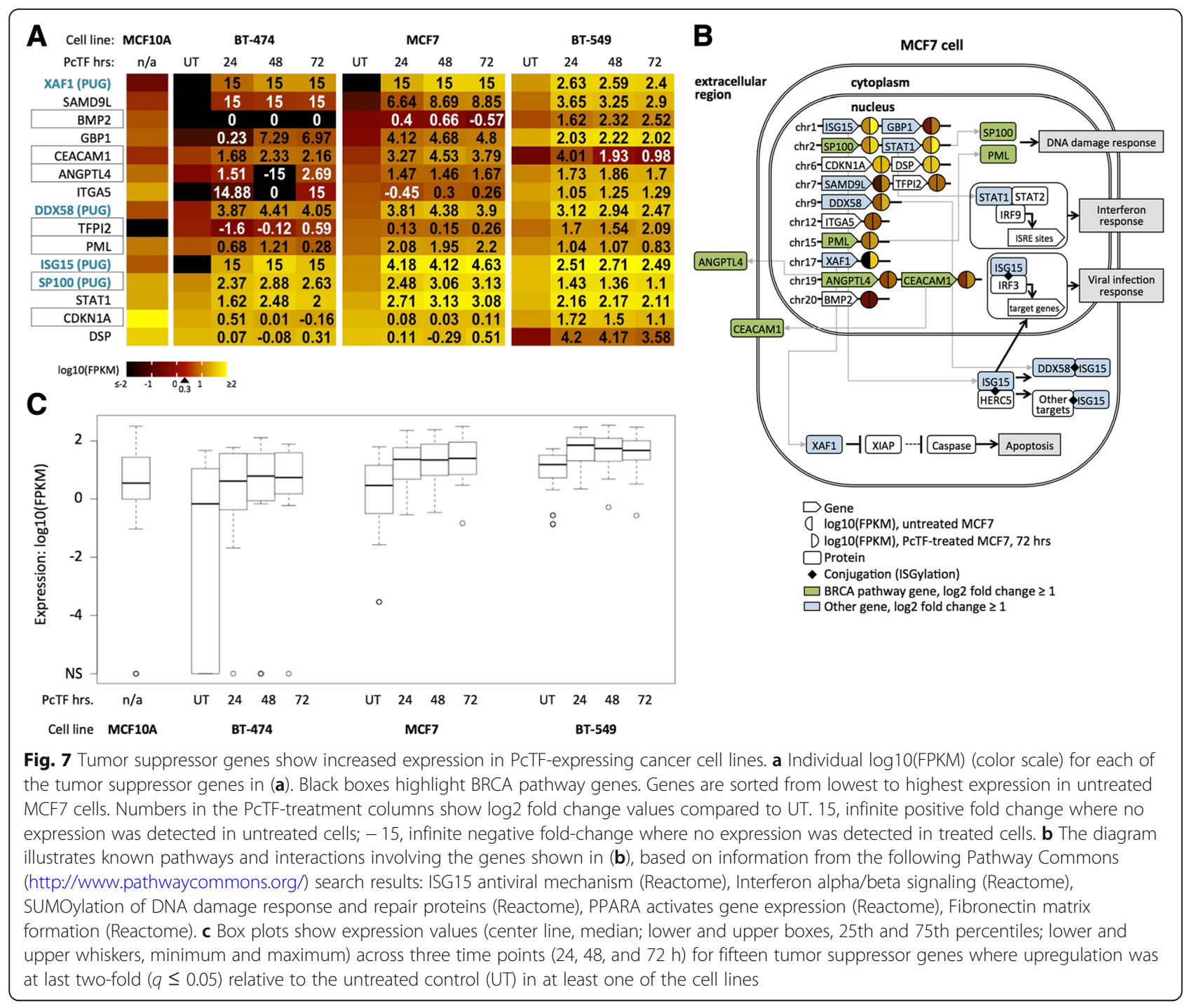

Cell line comparisons of RNA-seq FPKM values for the fifteen tumor suppressor genes showed that median expression was lower in untreated BT-474 and MCF7 than in the non-cancerous MCF10A cell line (Fig. 7c). This result is consistent with the idea that epigenetic repression of TSGs supports a cancerous cell phenotype. In PcTF-expressing cells, the median expression of the fifteen tumor suppressor genes was increased at all time points compared to the untreated samples for each cancer cell line (Fig. 7b). Interestingly, the median FPKM value for the 15 TSGs was higher in BT-549 than in MCF10A. Closer examination of the the individual genes revealed that expression levels for BMP2, CEACAM1, CDKN1A, DSP are lower in BT-549 than in MCF10A (Fig. 7a). These genes become upregulated in PcTF-expressing cells. These results demonstrate that PcTF stimulates conversion of the expression state of several tumor suppressor genes from silenced to active.

\section{Discussion}

As the importance of global chromatin-mediated dysregulation in oncogenesis is coming to light, scientists are becoming more interested in using inhibitors to block master regulators of repressive chromatin (i.e., HDACs, DNMTs, HMTs $[18,25,30,31,33])$ to investigate and treat cancer. This approach has been recently described as "macrogenomic engineering" [93]. A key advantage of broad epigenetic manipulation is that it is DNA sequence-agnostic; the therapeutic effect potentially does not require a priori knowledge of patient-specific sequence variations at candidate target genes. Cancer tissues often accumulate extensive DNA lesions, from small insertions and deletions to large chromosome rearrangements. Therefore, editing or activating single targets may not be effective in some cells. In this report we present a synthetic approach to macrogenomic engineering, a fusion protein that physically bridges a chromatin feature at silenced genes (H3K27me3) with proteins that 
drive gene activation. Our previous studies have established that PcTF specifically interacts with H3K27me3 in vitro [44], and drives the activation of hundreds of repressed loci including master regulators and tumor suppressors in bone, blood, and brain cancer derived model cell lines [45]. In our current report, we discovered a core set of interferon-pathway-related genes that responded to PcTF in three distinct breast cancer cell lines.

Several factors can contribute to transcriptomic variations in breast cancer subtypes, such as differences in the abundance of wild type or mutated transcription factors, mutations that impact the stability and turnover of RNA transcripts, and dysregulation of histone-modifying enzymes [13]. It is important to determine the relationship between phenotypic subclasses and transcription profiles $[16,64,94]$ to elucidate cancer mechanisms and drug targets for more effective treatments. Establishing a link between transcriptomes and phenotypes may require further research. We observed that the transcription profile of BT-549 (invasive basal B) is more similar to MCF7 (luminal) than either were to BT-474 (luminal). In contrast, other reports have shown clear distinctions between the transcription profiles and phenotypes of BT-549 and MCF7 [63]. Differences in transcript profiling methods, our RNA-seq and JSD analysis versus the DNA oligomer arrays used by others, may account for this conflicting result. Further, we acknowledge that the JSD may be driven by a few genes with high expression and high variance, which could account for some of the patterns.

Diversity of breast cancer cell transcriptomes poses a formidable challenge for the development of drugs that target specific proteins, genes, and pathways. Our results demonstrate that activation of a common set of genes can be achieved by direct targeting of H3K27me3 with a fusion activator (PcTF) in three distinct model breast cancer cell lines that show distinct basal gene-expression levels. The 19 common PcTF-upregulated genes (PUGs) show significant overrepresentation of the GO biological processes "defense response to virus" and "negative regulation of viral life cycle." A larger set of 125 genes that are upregulated at any time point in MCF7 (Figs. 4, 5) are associated with "type I interferon signaling pathway". Enrichments of H3K27me3 signals near the promoters of five PUGs (XAF1, HERC6, IFI44L, PLSCR1, IFI27) and a predicted regulator of all 19 PUGs (IRF1), suggest that PcTF accumulates near these promoters and recruits transcriptional activation machinery as demonstrated for CASZ1 in a previous study [45]. Another potential mechanism for stimulation of the IFN pathway is epigenetic de-repression of endogenous retroviral dsRNA production, as observed during treatments with inhibitors against DNA methyltransferases histone deacetylases [95-97]. It has been proposed that this process mimics a viral infection that makes the cancer cell a target for destruction by the immune system or immunotherapies [98].

While many H3K27me3-enriched genes were upregulated in MCF7, many were non-responsive under the conditions tested here (up to $72 \mathrm{~h}$ of PcTF expression). At PcTF-responsive genes, levels of H3K4me3 and H3K27ac were higher than at silenced non-responsive genes. Therefore, the chromatin at PcTF-responsive genes may support a low or intermediate expression state. Berrozpe et al. recently reported that Polycomb complexes preferentially accumulate at weakly expressed genes rather than strongly silenced or strongly expressed genes [76]. In our experiments, specific PRC-regulated genes may have been expressed at low to intermediate levels and then further upregulated upon exposure to PcTF. Our results also suggest that an initially high level of transgenic PcTF expression is sufficient to induce transcription at PUGs and other genes, even after PcTF transcript levels decrease at 48 and $72 \mathrm{~h}$ post-transfection (Fig. 3a). This behavior is consistent with a model supported by studies in stem cells, where transcriptional activation resolves the bivalent state into a committed, active epigenetic state [99, 100]. Our analysis of PcTF-regulated genes and chromatin states paves the way for future studies to further resolve chromatin features that distinguish regulatable PRC-repressed genes in cancer cells.

So far, low molecular weight compounds are the predominant method for epigenetic research and interventions. Their ease of delivery, orally or intravenously, make these compounds a very attractive approach for in vivo studies and cancer treatment. However, small compounds have a very limited range of biological activity, e.g. as ligands for specific proteins, compared to macromolecules. Transgenic and synthetic transcription factors expand the repertoire of epigenetic drug activity by allowing selective control of therapeutic genes in cancer cells [101-104]. Protein expression often relies on inefficient and possibly mutagenic nucleic acid delivery, which poses a significant barrier for many potential synthetic biologics. Recent advances in large molecule carriers such as cell penetrating peptides [105-107] provide a positive outlook for cellular delivery of purified proteins.

\section{Conclusions}

In conclusion, we have demonstrated that PcTF stimulates broad changes in expression, reminiscent of the effects observed for small-molecule epigenetic drugs, that could disrupt the immune evasion phenotype of cancer. Activation of IFN pathway genes has important implications for cancer research and therapy. Other studies have linked high levels of expression from interferon pathway genes with a non-cancerous phenotype. In breast cancer, expression of an immune response gene subgroup, which includes ISG15, MX1, and other 
interferon genes, has been associated with improved prognosis in triple negative breast cancers [28, 29]. It will be eventually important to determine if PcTF proteins meet or exceed the efficacy of low molecular weight epigenetic drugs in tumor and patient-derived models. At present, PcTF and its variants [44] represent a new exploration space for rationally-designed epigenetic interventions.

\section{Methods}

\section{DNA constructs}

Plasmids were constructed to express fusion proteins either constitutively or in the presence of doxycycline. The plasmid for constitutive expression of PcTF, hPCD-TF_MV2 (KAH126), was constructed as previously described [82]. The doxycycline-inducible transgene PcTF_pSBtet-GP was constructed by ligating $50 \mathrm{ng}$ of PCR amplified, Sfil-digested PcTF fragment with a Sfil-linearized pSBtet-GP vector [108] (Addgene \#60495) at a ratio of 5 insert to 1 vector in a $10 \mathrm{uL}$ reaction $(1 \mathrm{uL}$ $10 \times$ buffer, $1 \mathrm{uL}$ T4 ligase). The same procedure was used to build constructs for dox-inducible $\mathrm{Pc}_{\Delta} \mathrm{TF}$ expression. Primers used for the PCR amplification step are as follows: Forward 5'-tgaaGGCCTCTGAGGCCaattcgcggccgcatctaga, Reverse 5'-gcttGGCCTGACAGGCtgcagcggccgctactagt. Template-binding sequences are underscored. Adjacent nucleotides were designed to add SfiI restriction sites (uppercase) to each end. The full annotated sequences of all plasmids reported here are available online at Benchling - Hayneslab: Synthetic Chromatin Actuators (https://benchling.com/hayneslab/f/SOIOWLoRFK-syntheti c-chromatin-actuators/).

\section{Cell culture and transfection}

MCF7 (ATCC HTB-22) cells were cultured in Eagle's Minimal Essential Medium supplemented with 0.01 $\mathrm{mg} / \mathrm{mL}$ human recombinant insulin, $10 \%$ fetal bovine serum, and $1 \%$ penicillin and streptomyicn. BT-474 cells (ATCC HTB-20) were cultured in ATCC Hybri-Care Medium supplemented with $1.5 \mathrm{~g} / \mathrm{L}$ sodium bicarbonate, $10 \%$ fetal bovine serum, and $1 \%$ penicillin and streptomycin. BT-549 cells (ATCC HTB-122) were cultured in RPMI-1640 Medium supplemented with $0.0008 \mathrm{mg} / \mathrm{mL}$ human recombinant insulin, $10 \%$ fetal bovine serum, and $1 \%$ penicillin and streptomycin. MCF-10A cells (ATCC CRL-10317) were cultured in Mammary Epithelial Cell Growth Medium (Mammary Epithelial Cell Basal Medium and BulletKit supplements, except gentamycin-amphotericin B mix), supplemented with $100 \mathrm{ng} / \mathrm{mL}$ cholera toxin. Cells were grown at $37{ }^{\circ} \mathrm{C}$ in a humidified $\mathrm{CO}_{2}$ incubator. PcTF-expressing MCF7, BT-474, and BT-549 cells were generated by transfecting $5 \times 10^{5}$ cells in 6-well plates with DNA/Lipofectamine complexes: $2 \mu \mathrm{g}$ of
hPCD-TF_MV2 plasmid DNA, $7.5 \mu$ l of Lipofectamine LTX (Invitrogen), 2.5 PLUS reagent, $570 \mu \mathrm{l}$ OptiMEM. Control cells were mock-transfected with DNA-free water. Transfected cells were grown in pen/strep-free growth medium for $18 \mathrm{~h}$. The transfection medium was replaced with fresh, pen/strep-supplemented medium and cells were grown for up to $72 \mathrm{~h}$.

\section{Generation of stable cell lines}

To generate doxycycline-inducible cell lines, MCF7 cells were transfected with the transposase-expressing plasmid SB100X and either hPCD-TF_pSBtet-GP or TF_pSBtet-GP (19,1 M ratio of pSB to SB100X), under the same conditions as described above. After $24 \mathrm{~h}$, the transfection medium was replaced with fresh, puromycin-supplemented medium $(0.5 \mu \mathrm{g} / \mathrm{mL})$. Cells were then grown until cell cultures were $>90 \%$ GFP-positive as measured by flow cytometry. Total culture time was 2-3 weeks per cell line.

\section{Preparation of total mRNA}

Total messenger RNA was extracted from 90\% confluent cells $\left(\sim 1-2 \times 10^{6}\right)$. Adherent cells were lysed directly in culture plates with $500 \mu \mathrm{l}$ TRIzol. TRIzol cell lysates were extracted with $100 \mu \mathrm{l}$ chloroform and centrifuged at $12,000 \mathrm{xg}$ for $15 \mathrm{~min}$. at $4{ }^{\circ} \mathrm{C}$. RNA was column-purified from the aqueous phase (Qiagen RNeasy Mini kit 74,104).

\section{Reverse transcription PCR followed by quantitative PCR (RT-qPCR)}

SuperScript III (Invitrogen) was used to generate cDNA from $2.0 \mu \mathrm{g}$ of RNA. Real-time quantitative PCR reactions $(15 \mu \mathrm{l}$ each) contained $1 \times$ LightCycler 480 Probes Master Mix (Roche), 2.25 pmol of primers (see Additional file 1: Table S1 for sequences), and $2 \mu \mathrm{l}$ of a 1:10 cDNA dilution (1:1000 dilution for GAPDH and $\mathrm{mCh})$. The real time PCR program was run as follows: Pre-incubation, ramp at $4.4^{\circ} \mathrm{C}^{*} \mathrm{sec}^{-1}$ to $95^{\circ} \mathrm{C}$, hold $10 \mathrm{~min}$.; Amplification, 45 cycles (ramp at $4.4{ }^{\circ} \mathrm{C}^{*} \mathrm{sec}^{-1}$ to $95{ }^{\circ} \mathrm{C}$, hold $10 \mathrm{~s}$., ramp at $2.2{ }^{\circ} \mathrm{C}^{*} \mathrm{sec}^{-1}$ to $60^{\circ} \mathrm{C}$, hold $30 \mathrm{~s}$., single acquisition); Cooling, ramp at $2.2{ }^{\circ} \mathrm{C}^{*} \mathrm{sec}^{-1}$ to $40{ }^{\circ} \mathrm{C}$, hold $30 \mathrm{~s}$. Crossing point $\left(\mathrm{C}_{\mathrm{p}}\right)$ values, the first peak of the second derivative of fluorescence over cycle number, were calculated by the Roche LightCycler 480 software. Expression level was calculated as delta $C_{p}=2^{\wedge}\left[C_{p} G A P D H-C_{p}\right.$ experimental gene]. Fold change was determined as double delta $C_{p}=$ delta $C_{p}$ treated cells / delta $C_{p}$ mock for PcTF expression levels (Fig. 3c), or as double delta $C_{p}=C_{p}$ dox treated cells / delta $C_{p}$ no dox for gene expression levels in the stable cell lines (Fig. 3d).

\section{Transcriptome profiling with RNA-seq}

RNA-seq was performed using two biological replicates per cell type, treatment, and time point for 
transiently transfected cells and three replicates for untransfected MCF10A. Total RNA was prepared as described for RT-qPCR. 50 ng of total RNA was used to prepare cDNA via single primer isothermal amplification using the Ovation RNA-Seq System (Nugen 7102-A01) and automated on the Apollo 324 liquid handler (Wafergen). cDNA was sheared to approximately $300 \mathrm{bp}$ fragments using the Covaris M220 ultrasonicator. Libraries were generated using Kapa Biosystem's library preparation kit (KK8201). In separate reactions, fragments from each replicate sample were end-repaired, A-tailed, and ligated to index and adapter fragments (Bioo, 520,999). The adapter-ligated molecules were cleaned using AMPure beads (Agencourt Bioscience/ Beckman Coulter, A63883), and amplified with Kapa's HIFI enzyme. The library was analyzed on an Agilent Bioanalyzer, and quantified by qPCR (KAPA Library Quantification Kit, KK4835) before multiplex pooling and sequencing on a Hiseq 2000 platform (Illumina) at the ASU CLAS Genomics Core facility. Samples were sequenced at 8 per lane to generate an average of $2.5 \mathrm{E}+07$ reads per sample. Read values ranged from $5.7 \mathrm{E}+06$ (minimum) to $1.11 \mathrm{E}+08$ (maximum) per sample.

\section{Transcriptome analysis}

RNA-seq reads were quality-checked before and after trimming and filtering using FastQC [109]. TrimmomaticSE was used to clip bases that were below the PHRED-scaled threshold quality of 10 at the $5^{\prime}$ end and 25 at the trailing $3^{\prime}$ end of each read for all samples [110]. A sliding window of 4 bases was used to clip reads when the average quality per base dropped below 30. Reads of less than 50 bp were removed. A combined reference genome index and dictionary for GRCH38.p7 (1-22, X, MT, and non-chromosomal sequences) [111] that included the full coding region of the synthetic PcTF protein were created using Spliced Transcripts Alignment to Reference (STARv2.5.2b) [112] and the picard tools (version 1.1.19) [113]. Trimmed RNA-seq reads were mapped, and splice junctions extracted, using STARv2.5.2b read aligner [112]. Bamtools2.4.0 [114] was used to check alignment quality using the 'stats' command. Mapped reads in BAM format were sorted, duplicates were marked, read groups were added, and the files were indexed using the Bamtools 2.4.0 package. CuffDiff, a program in the Cufflinks package [66], was used to identify genes and transcripts that expressed significant changes in pairwise comparisons between conditions. Fastq and differential expression analysis files are available at the National Center for Biotechnology Information (NCBI) Gene Expression Omnibus (GEO) database (Accession GSE103520, release date September 8, 2017). CummeRbund [66] was used to calculate distances between features and to generate graphs and charts (JSD plots). $\mathrm{R}$ ggplot2 [111, 115] and VennDiagrams [116] were used to generate heat maps and Venn diagrams respectively. The entire workflow is provided as a readme file at: https://github.com/ WilsonSayresLab/PcTF_differential_expression

Bioinformatics analyses and sources of publicly shared data Chromatin immunoprecipitation followed by deep sequencing (ChIP-seq) data: For the results shown in Fig. 1b, H3K27me3 data for MCF7 cells was downloaded from the ENCODE project (accession UCSC-ENCODE-hg19:wgEncodeEH002922) [117]. We classified genes with a ChIP-seq peak within 5000 bp up or downstream of the transcription start site as H3K27me3-positive (1146 protein-coding transcripts). EZH2-enriched genes (2397 protein-coding transcripts) for MDA-MB-231 [16] were provided as a list from E. Benevolenskaya (unpublished). For the results shown in Fig. 5 and Additional file 1: Figure S6, MCF7 ChIP-seq data (from the P. Farnham, J. Stamatoyannopoulos, and V. Iyer labs) was downloaded from the ENCODE project [117]: H3K27me3 (ENCFF081UQC.bigWig), H3K9me3 (ENCFF754TEC.bigWig), H3K27ac (ENCFF986ZEW.bigWig), H3K 4me3 (ENCFF530LJW.bigWig), and RNA PolII (ENCFF690CUE.bam) and used to generate plots using DeepTools [118] (computeMatrix, plotProfile, plotHeatmap) in the Galaxy online platform at usega laxy.org [119]. Prior to plotting, the RNA PolII data was converted to bigWig format using bamCoverage. Gene ontology term enrichment: GOrilla analysis used the following parameters: organism, Homo sapiens; mode, target and background ranked list of genes; ontology, process; $p$-value threshold $=10.0 \mathrm{E}-3$ ) [70]. The background ranked list is available at https:// github.com/WilsonSayresLab/PcTF_differential_express ion. Panther analysis used the following parameters: analysis type, PANTHER Overrepresentation Test (Released 20,171,205); annotation version, PANTHER version 13.1 Released 2018-02-03; reference List, Homo sapiens (all genes in database); annotation data set, PANTHER GO-Slim biological process. Figure 3c was generated using REViGO [120] and GOrilla. Unique differentially expressed genes were analyzed using GeneCards [91]. Promoter motif analysis: The script TF_targets was downloaded from https:// github.com/cplaisier/TF_targets and used to find enriched transcription factor target sites that were determined by empirical evidence from chromatin studies across 68 cell lines [74]. Tumor suppressor genes: The results in Fig. 7 are based on human tumor suppressor genes (983 total) that are reported to show lower expressed in cancer samples of the Cancer 
Genome Atlas (TCGA) compared to the TCGA normal tissue samples was downloaded from https:// bioinfo.uth.edu/TSGene/download.cgi. Of these 983 genes, 589 are breast cancer specific $[89,90]$.

\section{Additional file}

Additional file 1: Figure S1. Comparisons of gene sets that are differentially or similarly expressed in BT-474, MCF7, BT-549, and MCF10A. Figure S2. Comparisons, by cell line, of expressed and silenced genes within PRC-modules. Figure S3. Jensen Shannon divergence analyses of transcription profiling data (RNA-seq) for all PCTF-treated and untreated cell samples. Figure S4. Detailed view of the transcription factor (TF) binding motif overrepresentation plot from Figure 3D. Figure S5. Expression levels of putative regulators of PUGs. Figure S6. Chromosome plot of PCTF-responsive genes that were identified in the RNA-seq experiment. Figure S7. Detailed view of MCF7 ChIP-seq signals. Table S1. The set of 45 H3K27me3-enriched, repressed (FPKM < 2) genes shared by the three cancer cell lines. Table S2. TF motif enrichment analysis results for the data shown in Fig. 3d. Table S3. Primers used to generate the RT-qPCR results shown in Fig. 6. (DOCX 3056 kb)

\section{Abbreviations}

CBX: Chromobox protein; DNMT: DNA methyltransferase; EZH2: Enhancer of zeste homologue 2; FPKM: RNA-seq fragments per kilobase million; $\mathrm{H} 3 \mathrm{~K} 27 \mathrm{ac}$ : Histone $\mathrm{H3}$ acetylated at lysine 27; H3K27me3: Histone H3 trimethylated at lysine 27; H3K4me3: Histone $\mathrm{H3}$ trimethylated at lysine 4; HDAC: Histone deacetylase; IFN: Interferon; PCD: Polycomb chromodomain; PCTF: Polycomb-based transcription factor; PRC: Polycomb repressive complex; PTM: Post-translational modification; RNA Polll: RNA polymerase 2 RNA-seq: RNA sequencing, or whole transcriptome sequencing; RTqPCR: Reverse transcription followed by quantitative PCR; TSG: Tumor suppressor gene

\section{Acknowledgements}

The authors thank Dr. E.V. Benevolenskaya for providing the MDA-MB-231 EZH2 gene module list and Dr. C. Plaisier for providing software and assistance with TF_targets and for critiques of the final manuscript.

\section{Funding}

MAWS and KCO were supported by a startup to MAWS from the School of Life Sciences and the Biodesign Institute at Arizona State University. DBN was supported by the Arizona Department of Health Services, Arizona Biomedical Research Commission (14-082976 to KAH). KAH was supported by the National Institutes of Health, National Cancer Institute (K01 CA188164 to KAH).

\section{Availability of data and materials}

The datasets generated and analysed during the current study are available in the NCBI Gene Expression Omnibus (GEO), accession GSE103520, https:// www.ncbi.nlm.nih.gov/geo/query/acc.cgi?acc=GSE103520

\section{Authors' contributions}

KCO performed differential expression transcriptome analysis, identification of targeted upregulated genes in response to PCTF, and submission of NGS data to the NCBI Gene Expression Omnibus (GEO). DBN performed cell culturing and transfection, preparation of samples for RNA-seq, and RT-qPCR. DAV completed transcription factor motif analyses. MAWS was responsible for the oversight of the bioinformatics analyses and interpretation of the data. $\mathrm{KAH}$ was responsible for the conception of the project, oversight of molecular cloning, cell culturing, and RNA-seq, and created the artwork for the figures. All authors read and approved the final manuscript.

\section{Ethics approval and consent to participate}

Not applicable

\section{Consent for publication}

Not applicable.

\section{Competing interests}

The authors declare that they have no competing interests.

\section{Publisher's Note}

Springer Nature remains neutral with regard to jurisdictional claims in published maps and institutional affiliations.

\section{Author details}

${ }^{1}$ School of Biological and Health Systems Engineering, Arizona State University, 501 E Tyler Mall, Tempe, AZ 85287-9709, USA. ${ }^{2}$ School of Life Sciences, Arizona State University, 427 E Tyler Mall, Tempe 85287-4501, AZ, USA. ${ }^{3}$ Center for Evolution and Medicine, Arizona State University, 427 E Tyler Mall, Tempe 85287-1701, AZ, USA.

Received: 6 April 2018 Accepted: 12 September 2018

Published online: 25 September 2018

\section{References}

1. Margueron R, Reinberg D. Chromatin structure and the inheritance of epigenetic information. Nat Rev Genet. 2010;11:285-96.

2. Richards EJ, Elgin SCR. Epigenetic codes for heterochromatin formation and silencing: rounding up the usual suspects. Cell. 2002:108:489-500.

3. Roemer I, Reik W, Dean W, Klose J. Epigenetic inheritance in the mouse. Curr Biol. 1997:7:277-80.

4. Cavalli G, Paro R. The Drosophila Fab-7 chromosomal element conveys epigenetic inheritance during mitosis and meiosis. Cell. 1998;93:505-18.

5. Kim J, Orkin SH. Embryonic stem cell-specific signatures in cancer: insights into genomic regulatory networks and implications for medicine. Genome Med. 2011;3:75.

6. Sparmann A, van Lohuizen M. Polycomb silencers control cell fate, development and cancer. Nat Rev Cancer. 2006;6:846-56.

7. Wang W, Qin J-J, Voruganti S, Nag S, Zhou J, Zhang R. Polycomb Group (PcG) Proteins and Human Cancers: Multifaceted Functions and Therapeutic Implications. Med Res Rev. 2015;35:1220-67.

8. Chang C-J, Yang J-Y, Xia W, Chen C-T, Xie X, Chao C-H, et al. EZH2 promotes expansion of breast tumor initiating cells through activation of RAF1- $\beta$-catenin signaling. Cancer Cell. 2011;19:86-100.

9. Alford SH, Toy K, Merajver SD, Kleer CG. Increased risk for distant metastasis in patients with familial early-stage breast cancer and high EZH2 expression. Breast Cancer Res Treat. 2012;132:429-37.

10. Kleer CG, Cao Q, Varambally S, Shen R, Ota I, Tomlins SA, et al. EZH2 is a marker of aggressive breast cancer and promotes neoplastic transformation of breast epithelial cells. Proc Natl Acad Sci U S A. 2003;100:11606-11.

11. Niida A, Smith AD, Imoto S, Aburatani H, Zhang MQ, Akiyama T. Gene setbased module discovery in the breast cancer transcriptome. BMC Bioinformatics. 2009:10:71

12. Collett K, Eide GE, Arnes J, Stefansson IM, Eide J, Braaten A, et al. Expression of enhancer of zeste homologue 2 is significantly associated with increased tumor cell proliferation and is a marker of aggressive breast cancer. Clin Cancer Res. 2006;12:1168-74.

13. Peña-Llopis S, Wan Y, Martinez ED. Unique epigenetic gene profiles define human breast cancers with poor prognosis. Oncotarget. 2016;7:85819-31.

14. Gao Z, Zhang J, Bonasio R, Strino F, Sawai A, Parisi F, et al. PCGF homologs, CBX proteins, and RYBP define functionally distinct PRC1 family complexes. Mol Cell. 2012:45:344-56.

15. Easwaran H, Johnstone SE, Van Neste L, Ohm J, Mosbruger T, Wang Q, et al. A DNA hypermethylation module for the stem/progenitor cell signature of cancer. Genome Res. 2012;22:837-49.

16. Jene-Sanz A, Varaljai R, Vilkova AV, Khramtsova GF, Khramtsov Al, Olopade Ol, et al. Expression of Polycomb Targets Predicts Breast Cancer Prognosis. Mol Cell Biol. 2013;33:3951-61.

17. Bracken AP, Helin K. Polycomb group proteins: navigators of lineage pathways led astray in cancer. Nat Rev Cancer. 2009;9:773-84.

18. Dawson MA, Kouzarides T. Cancer epigenetics: from mechanism to therapy. Cell. 2012;150:12-27

19. Tabet S, Douglas SF, Daze KD, Garnett GAE, Allen KJH, Abrioux EMM, et al. Synthetic trimethyllysine receptors that bind histone 3, trimethyllysine 27 $(\mathrm{H} 3 \mathrm{~K} 27 \mathrm{me} 3)$ and disrupt its interaction with the epigenetic reader protein CBX7. Bioorg Med Chem. 2013;21:7004-10. 
20. Simhadri C, Daze KD, Douglas SF, Quon TTH, Dev A, Gignac MC, et al. Chromodomain antagonists that target the polycomb-group methyllysine reader protein chromobox homolog 7 (CBX7). J Med Chem. 2014;57:2874-83.

21. Stuckey Jl, Dickson BM, Cheng N, Liu Y, Norris JL, Cholensky SH, et al. A cellular chemical probe targeting the chromodomains of Polycomb repressive complex 1. Nat Chem Biol. 2016;12:180-7.

22. Lee J, Wang A, Hu Q, Lu S, Dong Z. Adenovirus-mediated interferon- $\beta$ gene transfer inhibits angiogenesis in and progression of orthotopic tumors of human prostate cancer cells in nude mice. Int J Oncol. 2006. https://doi.org/ 10.3892/ijo.29.6.1405.

23. Bouker KB, Skaar TC, Riggins RB, Harburger DS, Fernandez DR, Zwart A, et al. Interferon regulatory factor-1 (IRF-1) exhibits tumor suppressor activities in breast cancer associated with caspase activation and induction of apoptosis. Carcinogenesis. 2005;26:1527-35.

24. Ikeda H, Old LJ, Schreiber RD. The roles of IFN gamma in protection against tumor development and cancer immunoediting. Cytokine Growth Factor Rev. 2002:13:95-109.

25. Dunn J, Rao S. Epigenetics and immunotherapy: The current state of play. Mol Immunol. 2017;87:227-39.

26. Kulaeva OI, Draghici S, Tang L, Kraniak JM, Land SJ, Tainsky MA. Epigenetic silencing of multiple interferon pathway genes after cellular immortalization. Oncogene. 2003;22:4118-27.

27. McGough JM, Yang D, Huang S, Georgi D, Hewitt SM, Röcken C, et al. DNA methylation represses IFN-gamma-induced and signal transducer and activator of transcription 1-mediated IFN regulatory factor 8 activation in colon carcinoma cells. Mol Cancer Res. 2008;6:1841-51.

28. Teschendorff AE, Miremadi A, Pinder SE, Ellis IO, Caldas C. An immune response gene expression module identifies a good prognosis subtype in estrogen receptor negative breast cancer. Genome Biol. 2007;8:R157.

29. Xu H, Xian J, Vire E, McKinney S, Wei V, Wong J, et al. Up-regulation of the interferonrelated genes in BRCA2 knockout epithelial cells. J Pathol. 2014;234:386-97.

30. Li H, Chiappinelli KB, Guzzetta AA, Easwaran H, Yen R-WC, Vatapalli R, et al. Immune regulation by low doses of the DNA methyltransferase inhibitor 5azacitidine in common human epithelial cancers. Oncotarget. 2014;5:587-98.

31. Stone ML, Chiappinelli KB, Li H, Murphy LM, Travers ME, Topper MJ, et al. Epigenetic therapy activates type I interferon signaling in murine ovarian cancer to reduce immunosuppression and tumor burden. Proc Natl Acad Sci U S A. 2017. https://doi.org/10.1073/pnas.1712514114.

32. Biancotto $C$, Frigè $G$, Minucci $S$. Histone modification therapy of cancer. Adv Genet. 2010;70:341-86.

33. Mani S, Herceg Z. DNA demethylating agents and epigenetic therapy of cancer. Adv Genet. 2010;70:327-40.

34. McGarvey KM, Fahrner JA, Greene E, Martens J, Jenuwein T, Baylin SB. Silenced Tumor Suppressor Genes Reactivated by DNA Demethylation Do Not Return to a Fully Euchromatic Chromatin State. Cancer Res. 2006;66:3541-9.

35. McGarvey KM, Greene E, Fahrner JA, Jenuwein T, Baylin SB. DNA methylation and complete transcriptional silencing of cancer genes persist after depletion of EZH2. Cancer Res. 2007;67:5097-102.

36. Su I-H, Dobenecker M-W, Dickinson E, Oser M, Basavaraj A, Marqueron R, et al. Polycomb group protein ezh2 controls actin polymerization and cell signaling. Cell. 2005;121:425-36.

37. Ueda K, Yoshimi A, Kagoya Y, Nishikawa S, Marquez VE, Nakagawa M, et al. Inhibition of histone methyltransferase EZH2 depletes leukemia stem cell of mixed lineage leukemia fusion leukemia through upregulation of p16. Cancer Sci. 2014:105:512-9.

38. Xu B, On DM, Ma A, Parton T, Konze KD, Pattenden SG, et al. Selective inhibition of EZH2 and EZH1 enzymatic activity by a small molecule suppresses MLL-rearranged leukemia. Blood. 2015;125:346-57.

39. Fujiwara T, Saitoh H, Inoue A, Kobayashi M, Okitsu Y. Katsuoka Y, et al. 3Deazaneplanocin A (DZNep), an inhibitor of S-adenosylmethioninedependent methyltransferase, promotes erythroid differentiation. J Biol Chem. 2014;289:8121-34.

40. Wu G, Broniscer A, McEachron TA, Lu C, Paugh BS, Becksfort J, et al. Somatic histone $\mathrm{H} 3$ alterations in pediatric diffuse intrinsic pontine gliomas and non-brainstem glioblastomas. Nat Genet. 2012;44:251-3.

41. Schwartzentruber J, Korshunov A, Liu X-Y, Jones DTW, Pfaff E, Jacob K, et al. Driver mutations in histone $\mathrm{H} 3.3$ and chromatin remodelling genes in paediatric glioblastoma. Nature. 2012;482:226-31.

42. Chan KM, Han J, Fang D, Gan H, Zhang Z. A lesson learned from the H3. 3K27M mutation found in pediatric glioma: a new approach to the study of the function of histone modifications in vivo? Cell Cycle. 2013;12:2546-52.
43. Chan K-M, Fang D, Gan H, Hashizume R, Yu C, Schroeder M, et al. The histone H3.3K27M mutation in pediatric glioma reprograms H3K27 methylation and gene expression. Genes Dev. 2013;27:985-90.

44. Tekel SJ, Vargas DA, Song L, LaBaer J, Haynes KA. Tandem histone-binding domains enhance the activity of a synthetic chromatin effector. 2017. https://doi.org/10.1101/145730.

45. Nyer DB, Daer RM, Vargas D, Hom C, Haynes KA. Regulation of cancer epigenomes with a histone-binding synthetic transcription factor. NPJ Genomic Med. 2017;2. https://doi.org/10.1038/541525-016-0002-3.

46. Neve RM, Chin K, Fridlyand J, Yeh J, Baehner FL, Fevr T, et al. A collection of breast cancer cell lines for the study of functionally distinct cancer subtypes. Cancer Cell. 2006;10:515-27.

47. Lacroix M, Leclercq G. Relevance of breast cancer cell lines as models for breast tumours: an update. Breast Cancer Res Treat. 2004;83:249-89.

48. Goodspeed A, Heiser LM, Gray JW, Costello JC. Tumor-Derived Cell Lines as Molecular Models of Cancer Pharmacogenomics. Mol Cancer Res. 2016;14:3-13.

49. Lehmann BD, Bauer JA, Chen X, Sanders ME, Chakravarthy AB, Shyr Y, et al. Identification of human triple-negative breast cancer subtypes and preclinical models for selection of targeted therapies. J Clin Invest. 2011;121: 2750-67.

50. Tseng L-M, Chiu J-H, Liu C-Y, Tsai Y-F, Wang Y-L, Yang C-W, et al. A comparison of the molecular subtypes of triple-negative breast cancer among non-Asian and Taiwanese women. Breast Cancer Res Treat. 2017; 163:241-54.

51. Nagaraja GM, Othman M, Fox BP, Alsaber R, Pellegrino CM, Zeng Y, et al. Gene expression signatures and biomarkers of noninvasive and invasive breast cancer cells: comprehensive profiles by representational difference analysis, microarrays and proteomics. Oncogene. 2006;25:2328-38.

52. Sorlie T, Tibshirani R, Parker J, Hastie T, Marron JS, Nobel A, et al. Repeated observation of breast tumor subtypes in independent gene expression data sets. Proc Natl Acad Sci U S A. 2003;100:8418-23.

53. Sorlie T, Perou CM, Tibshirani R, Aas T, Geisler S, Johnsen H, et al. Gene expression patterns of breast carcinomas distinguish tumor subclasses with clinical implications. Proc Natl Acad Sci. 2001:98:10869-74.

54. Ben-Porath I, Thomson MW, Carey VJ, Ge R, Bell GW, Regev A, et al. An embryonic stem cell-like gene expression signature in poorly differentiated aggressive human tumors. Nat Genet. 2008;40:499-507.

55. Boyer LA, Plath K, Zeitlinger J, Brambrink T, Medeiros LA, Lee TI, et al. Polycomb complexes repress developmental regulators in murine embryonic stem cells. Nature. 2006:441:349-53.

56. Lee TI, Jenner RG, Boyer LA, Guenther MG, Levine SS, Kumar RM, et al. Control of developmental regulators by Polycomb in human embryonic stem cells. Cell. 2006;125:301-13.

57. Zuo T, Liu T-M, Lan X, Weng Y-I, Shen R, Gu F, et al. Epigenetic silencing mediated through activated PI3KJAKT signaling in breast cancer. Cancer Res. 2011;71:1752-62.

58. Lin H-JL, Zuo T, Lin C-H, Kuo CT, Liyanarachchi S, Sun S, et al. Breast cancerassociated fibroblasts confer AKT1-mediated epigenetic silencing of Cystatin M in epithelial cells. Cancer Res. 2008:68:10257-66.

59. Ren G, Baritaki S, Marathe H, Feng J, Park S, Beach S, et al. Polycomb protein $\mathrm{EZH} 2$ regulates tumor invasion via the transcriptional repression of the metastasis suppressor RKIP in breast and prostate cancer. Cancer Res. 2012; 72:3091-104.

60. Leroy G, Dimaggio PA, Chan EY, Zee BM, Blanco MA, Bryant B, et al. A quantitative atlas of histone modification signatures from human cancer cells. Epigenetics Chromatin. 2013;6:20.

61. Derfoul A, Juan AH, Difilippantonio MJ, Palanisamy N, Ried T, Sartorelli V. Decreased microRNA-214 levels in breast cancer cells coincides with increased cell proliferation, invasion and accumulation of the Polycomb Ezh2 methyltransferase. Carcinogenesis. 2011;32:1607-14.

62. Dong M, Fan X-J, Chen Z-H, Wang T-T, Li X, Chen J, et al. Aberrant expression of enhancer of zeste homologue 2, correlated with HIF-1a, refines relapse risk and predicts poor outcome for breast cancer. Oncol Rep. 2014;32:1101-7.

63. Kenny PA, Lee GY, Myers CA, Neve RM, Semeiks JR, Spellman PT, et al. The morphologies of breast cancer cell lines in three-dimensional assays correlate with their profiles of gene expression. Mol Oncol. 2007;1:84-96.

64. Seals DF, Azucena EF, Pass I Jr, Tesfay L, Gordon R, Woodrow M, et al. The adaptor protein Tks5/Fish is required for podosome formation and function, and for the protease-driven invasion of cancer cells. Cancer Cell. 2005;7: $155-65$. 
65. Zhao S, Fung-Leung W-P, Bittner A, Ngo K, Liu X. Comparison of RNA-Seq and microarray in transcriptome profiling of activated T cells. PLoS One. 2014;9:e78644.

66. Trapnell C, Roberts A, Goff L, Pertea G, Kim D, Kelley DR, et al. Differential gene and transcript expression analysis of RNA-seq experiments with TopHat and Cufflinks. Nat Protoc. 2012;7:562-78.

67. Trapnell C, Hendrickson DG, Sauvageau M, Goff L, Rinn JL, Pachter L. Differential analysis of gene regulation at transcript resolution with RNA-seq. Nat Biotechnol. 2013;31:46-53.

68. Gonzàlez-Porta M, Frankish A, Rung J, Harrow J, Brazma A. Transcriptome analysis of human tissues and cell lines reveals one dominant transcript per gene. Genome Biol. 2013;14:R70.

69. Rupp SM, Webster TH, Olney KC, Hutchins ED, Kusumi K, Wilson Sayres MA. Evolution of Dosage Compensation in Anolis carolinensis, a Reptile with XX/ XY Chromosomal Sex Determination. Genome Biol Evol. 2017:9:231-40.

70. Eden E, Navon R, Steinfeld I, Lipson D, Yakhini Z. GOrilla: a tool for discovery and visualization of enriched $\mathrm{GO}$ terms in ranked gene lists. BMC Bioinformatics. 2009;10:48.

71. Mi H, Huang X, Muruganujan A, Tang H, Mills C, Kang D, et al. PANTHER version 11: expanded annotation data from Gene Ontology and Reactome pathways, and data analysis tool enhancements. Nucleic Acids Res. 2017;45:D183-9.

72. Jardim BV, Moschetta MG, Leonel C, Gelaleti GB, Regiani VR, Ferreira LC, et al. Glutathione and glutathione peroxidase expression in breast cancer: an immunohistochemical and molecular study. Oncol Rep. 2013;30:1119-28.

73. Fürstenberger G, Krieg P, Müller-Decker K, Habenicht AJR. What are cyclooxygenases and lipoxygenases doing in the driver's seat of carcinogenesis? Int J Cancer. 2006;119:2247-54.

74. Plaisier CL, O'Brien S, Bernard B, Reynolds S, Simon Z, Toledo CM, et al Causal Mechanistic Regulatory Network for Glioblastoma Deciphered Using Systems Genetics Network Analysis. Cell Syst. 2016;3:172-86.

75. Simon JA, Kingston RE. Mechanisms of polycomb gene silencing: knowns and unknowns. Nat Rev Mol Cell Biol. 2009;10:697-708.

76. Berrozpe G, Bryant GO, Warpinski K, Spagna D, Narayan S, Shah S, et al. Polycomb Responds to Low Levels of Transcription. Cell Rep. 2017;20:785-93.

77. Lachner M, Sengupta R, Schotta G, Jenuwein T. Trilogies of histone lysine methylation as epigenetic landmarks of the eukaryotic genome. Cold Spring Harb Symp Quant Biol. 2004;69:209-18.

78. Haynes KA, Leibovitch BA, Rangwala SH, Craig C, Elgin SCR. Analyzing heterochromatin formation using chromosome 4 of Drosophila melanogaster. Cold Spring Harb Symp Quant Biol. 2004;69:267-72.

79. Nishibuchi G, Déjardin J. The molecular basis of the organization of repetitive DNA-containing constitutive heterochromatin in mammals. Chromosome Res. 2017;25:77-87.

80. Wiles ET, Selker EU. H3K27 methylation: a promiscuous repressive chromatin mark. Curr Opin Genet Dev. 2017;43:31-7.

81. Zaidi SK, Frietze SE, Gordon JA, Heath JL, Messier T, Hong D, et al. Bivalent Epigenetic Control of Oncofetal Gene Expression in Cancer. Mol Cell Biol. 2017;37. https://doi.org/10.1128/MCB.00352-17.

82. Haynes KA, Silver PA. Synthetic reversal of epigenetic silencing. J Biol Chem. 2011;286:27176-82.

83. Leonova K, Safina A, Nesher E, Sandlesh P, Pratt R, Burkhart C, et al. TRAIN (Transcription of Repeats Activates INterferon) in response to chromatin destabilization induced by small molecules in mammalian cells. Elife. 2018;7. https://doi.org/10.7554/eLife.30842.

84. Sledz CA, Holko M, de Veer MJ, Silverman RH, Williams BRG. Activation of the interferon system by short-interfering RNAs. Nat Cell Biol. 2003;5:834-9.

85. Olejniczak M, Galka P, Krzyzosiak WJ. Sequence-non-specific effects of RNA interference triggers and microRNA regulators. Nucleic Acids Res. 2010;38:1-16.

86. Fiszer-Kierzkowska A, Vydra N, Wysocka-Wycisk A, Kronekova Z, Jarząb M, Lisowska KM, et al. Liposome-based DNA carriers may induce cellular stress response and change gene expression pattern in transfected cells. BMC Mol Biol. 2011;12:27.

87. Jacobsen L, Calvin S, Lobenhofer E. Transcriptional effects of transfection: the potential for misinterpretation of gene expression data generated from transiently transfected cells. Biotechniques. 2009;47:617-24.

88. Huerfano S, Ryabchenko B, Forstová J. Nucleofection of expression vectors induces a robust interferon response and inhibition of cell proliferation. DNA Cell Biol. 2013;32:467-79.

89. Zhao M, Sun J. TSGene: a web resource for tumor suppressor genes. Nucleic Acids Res. 2013;41:D970-6 Database issue.
90. Zhao M, Kim P, Mitra R, Zhao J, Zhao Z. TSGene 2.0: an updated literaturebased knowledgebase for tumor suppressor genes. Nucleic Acids Res. 2015 44:D1023-31.

91. Rebhan M, Chalifa-Caspi V, Prilusky J, Lancet D. GeneCards: integrating information about genes, proteins and diseases. Trends Genet. 1997;13:163.

92. Cerami EG, Gross BE, Demir E, Rodchenkov I, Babur O, Anwar N, et al. Pathway Commons, a web resource for biological pathway data. Nucleic Acids Res. 2011;39(Database issue):D685-90.

93. Almassalha LM, Bauer GM, Wu W, Cherkezyan L, Zhang D, Kendra A, et al. Macrogenomic engineering via modulation of the scaling of chromatin packing density. Nat Biomed Eng. 2017;1:902-13.

94. Guo X, Xiao H, Guo S, Dong L, Chen J. Identification of breast cancer mechanism based on weighted gene coexpression network analysis. Cancer Gene Ther. 2017. https://doi.org/10.1038/cgt.2017.23.

95. Chiappinelli KB, Strissel PL, Desrichard A, Li H, Henke C, Akman B, et al. Inhibiting DNA Methylation Causes an Interferon Response in Cancer via dsRNA Including Endogenous Retroviruses. Cell. 2015;162:974-86.

96. Roulois D, Loo Yau H, Singhania R, Wang Y, Danesh A, Shen SY, et al. DNADemethylating Agents Target Colorectal Cancer Cells by Inducing Viral Mimicry by Endogenous Transcripts. Cell. 2015;162:961-73.

97. Brocks D, Schmidt CR, Daskalakis M, Jang HS, Shah NM, Li D, et al. DNMT and HDAC inhibitors induce cryptic transcription start sites encoded in long terminal repeats. Nat Genet. 2017;49:1052-60.

98. Classon M, LaMarco K, De Carvalho DD. Drug-induced activation of "junk" DNA - A path to combat cancer therapy resistance? Oncoscience. 2017;4: $115-6$.

99. Gao Y, Gan H, Lou Z, Zhang Z. Asfla resolves bivalent chromatin domains for the induction of lineage-specific genes during mouse embryonic stem cell differentiation. Proc Natl Acad Sci U S A. 2018;115:E6162-71.

100. Bernstein BE, Mikkelsen TS, Xie X, Kamal M, Huebert DJ, Cuff J, et al. A bivalent chromatin structure marks key developmental genes in embryonic stem cells. Cell. 2006;125:315-26.

101. Kwilas AR, Ardiani A, Dirmeier U, Wottawah C, Schlom J, Hodge JW. A poxviral-based cancer vaccine the transcription factor twist inhibits primary tumor growth and metastases in a model of metastatic breast cancer and improves survival in a spontaneous prostate cancer model. Oncotarget. 2015;6:28194-210.

102. Beltran A, Parikh S, Liu Y, Cuevas BD, Johnson GL, Futscher BW, et al. Reactivation of a dormant tumor suppressor gene maspin by designed transcription factors. Oncogene. 2007;26:2791-8.

103. Falke $D$, Fisher $M, Y e ~ D$, Juliano RL. Design of artificial transcription factors to selectively regulate the pro-apoptotic bax gene. Nucleic Acids Res. 2003; 31:e10.

104. Lara H, Wang Y, Beltran AS, Juárez-Moreno K, Yuan X, Kato S, et al. Targeting serous epithelial ovarian cancer with designer zinc finger transcription factors. J Biol Chem. 2012;287:29873-86.

105. Akishiba M, Takeuchi T, Kawaguchi Y, Sakamoto K, Yu H-H, Nakase I, et al. Cytosolic antibody delivery by lipid-sensitive endosomolytic peptide. Nat Chem. 2017:9:751-61.

106. Essafi M, Baudot AD, Mouska X, Cassuto J-P, Ticchioni M, Deckert M. Cellpenetrating TAT-FOXO3 fusion proteins induce apoptotic cell death in leukemic cells. Mol Cancer Ther. 2011;10:37-46.

107. Staahl BT, Benekareddy M, Coulon-Bainier C, Banfal AA, Floor SN, Sabo JK, et al. Efficient genome editing in the mouse brain by local delivery of engineered Cas9 ribonucleoprotein complexes. Nat Biotechnol. 2017;35:431-4.

108. Kowarz E, Löscher D, Marschalek R. Optimized Sleeping Beauty transposons rapidly generate stable transgenic cell lines. Biotechnol J. 2015;10:647-53.

109. Andrews S. FastQC: a quality control tool for high throughput sequence data. Babraham Bioinformatics. 2010; http://www.bioinformatics.babraham. ac.uk/projects/fastqc/.

110. Bolger AM, Lohse M, Usadel B. Trimmomatic: a flexible trimmer for Illumina sequence data. Bioinformatics. 2014;30:2114-20.

111. Harrow J, Frankish A, Gonzalez JM, Tapanari E, Diekhans M, Kokocinski F, et al. GENCODE: the reference human genome annotation for The ENCODE Project. Genome Res. 2012;22:1760-74.

112. Dobin A, Davis CA, Schlesinger F, Drenkow J, Zaleski C, Jha S, et al. STAR: ultrafast universal RNA-seq aligner. Bioinformatics. 2013;29:15-21.

113. Picard Tools. Broad Institute. 2003. http://broadinstitute.github.io/picard/.

114. Barnett DW, Garrison EK, Quinlan AR, Strömberg MP, Marth GT. BamTools: a $\mathrm{C}++\mathrm{API}$ and toolkit for analyzing and managing BAM files. Bioinformatics. 2011;27:1691-2. 
115. Warnes MGR, Bolker B, Bonebakker L, Gentleman R. Package "gplots". Various R Programming Tools for Plotting Data 2016.

116. Chen H, Boutros PC. VennDiagram: a package for the generation of highlycustomizable Venn and Euler diagrams in R. BMC Bioinformatics. 2011:12:35.

117. ENCODE Project Consortium. An integrated encyclopedia of DNA elements in the human genome. Nature. 2012;489:57-74.

118. Ramírez F, Ryan DP, Grüning B, Bhardwaj V, Kilpert F. Richter AS, et al. deepTools2: a next generation web server for deep-sequencing data analysis. Nucleic Acids Res. 2016;44:W160-5.

119. Afgan E, Baker D, van den Beek M, Blankenberg D, Bouvier D, Čech M, et al. The Galaxy platform for accessible, reproducible and collaborative biomedical analyses: 2016 update. Nucleic Acids Res. 2016;44:W3-10.

120. Supek F, Bošnjak M, Škunca N, Šmuc T. REVIGO summarizes and visualizes long lists of gene ontology terms. PLoS One. 2011;6:e21800.

Ready to submit your research? Choose BMC and benefit from:

- fast, convenient online submission

- thorough peer review by experienced researchers in your field

- rapid publication on acceptance

- support for research data, including large and complex data types

- gold Open Access which fosters wider collaboration and increased citations

- maximum visibility for your research: over $100 \mathrm{M}$ website views per year

At $\mathrm{BMC}$, research is always in progress.

Learn more biomedcentral.com/submissions 